\title{
Growth Hormone Reduces the Severity of Fibrosis Associated With Chronic Intestinal Inflammation
}

\author{
ARIANNE L. THEISS,* C. RANDALL FULLER,* JAMES G. SIMMONS,* BO LIU, ${ }^{\dagger}$ \\ R. BALFOUR SARTOR, ${ }^{\neq}$, I and P. KAY LUND*,§, \\ *Departments of Cell and Molecular Physiology, ${ }^{\star}$ Medicine, Microbiology and Immunology, and \$Pediatrics, and the ${ }^{\mathbb{9}}$ Center for \\ Gastrointestinal Biology and Disease, The University of North Carolina at Chapel Hill, Chapel Hill, North Carolina
}

Background \& Aims: Growth hormone (GH) is used to treat growth delay in children with Crohn's disease and in patients with short-bowel syndrome. GH can increase collagen accumulation in intestinal mesenchymal cells, raising concern that $\mathrm{GH}$ therapy could exacerbate fibrosis in patients with Crohn's disease. We tested if GH treatment altered inflammation or fibrosis during chronic, experimental granulomatous enterocolitis. Methods: lleum and cecum of Lewis rats were subserosally injected with peptidoglycan-polysaccharide (PGAPS) or control human serum albumin. At the onset of chronic PG-APS-induced inflammation, rats were administered recombinant human GH or vehicle for 14 days. Fibrosis and inflammation were quantified by gross gut disease scoring, histologic scoring, type I collagen, and cytokine expression in cecum. Abundance and localization of suppressor of cytokine signaling-3 (SOCS-3) messenger RNA and/or protein were determined in cecum. Effect of GH, cytokines, or PG-APS on SOCS-3 synthesis was measured in intestinal myofibroblasts. Myofibroblasts overexpressing SOCS-3 were used to test whether SOCS-3 inhibits collagen accumulation. Results: In PG-APS-injected rats, GH modestly reduced gross adhesions and mesenteric contractions, cecal fibrosis score, and collagen expression, but had no effect on intestinal inflammation. GH increased SOCS-3 messenger RNA and protein abundance in PG-APS rats and SOCS-3 messenger RNA was localized to the periphery of granulomas. GH in combination with cytokines or PG-APS, but not alone, induced SOCS-3 synthesis in intestinal myofibroblasts. Myofibroblasts overexpressing SOCS-3 showed reduced cytokine-induced collagen accumulation. Conclusions: GH modestly reduces intestinal fibrosis associated with chronic experimental enterocolitis and stimulates expression of antifibrogenic SOCS-3, suggesting that GH therapy in inflammatory bowel disease should not exacerbate fibrosis.

$I^{\prime}$ ntestinal fibrosis is a common complication of Crohn's disease (CD) and generally is considered an excessive, irreversible, wound-healing response to chronic transmural inflammation. ${ }^{1}$ Fibrosis in this disorder involves over- growth of the muscularis mucosa and muscularis propria, ${ }^{2}$ excessive collagen deposition, ${ }^{2,3}$ and mesenchymal cell hyperplasia. ${ }^{4-6}$ Although fibrosis is variable in presentation in $\mathrm{CD}$, it can lead to stricture and partial or complete bowel obstruction, which are serious complications for which endoscopic balloon dilation or surgical resection are the only current therapies. ${ }^{7,8}$ Unfortunately, high recurrence of inflammation and fibrosis in CD patients contributes to repeat surgeries and complications and can result in short-bowel syndrome (SBS), a malabsorption syndrome resulting from insufficient functional bowel. 7,8

Recombinant human growth hormone (rhGH), alone or in combination with glutamine and modified diet, has been tested as therapy in SBS patients in a number of clinical trials and was reported to improve weight gain and lean body mass and reduce the need for parenteral nutrition. ${ }^{9-13}$ Clinical trials of $\mathrm{rhGH}$ in SBS patients reported varied outcomes on nutrient absorption and provided no consistent evidence about direct effects of $\mathrm{GH}$ on intestinal function or growth. , $^{9114-16}$ The use of rhGH in SBS patients remains controversial, despite recent Food and Drug Administration approval. ${ }^{17}$ Some SBS patients treated with rhGH had CD, but no information was reported regarding rhGH effects on inflammation or fibrosis. ${ }^{9,10}$ rhGH therapy improved linear growth in pediatric CD patients with growth delay. ${ }^{18,19}$ A clinical trial of a small number of patients with active $\mathrm{CD}$ reported that GH therapy in concert with a highprotein diet improved disease symptoms measured by the Crohn's Disease Activity Index and decreased the need

Abbreviations used in this paper: GAPDH, glyceraldehyde-3-phosphate dehydrogenase; HSA, human serum albumin; IGF-I, insulin-like growth factor; IL, interleukin; PG-APS, peptidoglycan-polysaccharide; rhGH, recombinant human growth hormone; SBS, short bowel syndrome; SOCS-3, suppressor of cytokine signaling-3; TNF $\alpha$, tumor necrosis factor $\alpha$.

(C) 2005 by the American Gastroenterological Association 0016-5085/05/\$30.00 doi:10.1053/j.gastro.2005.05.019 
for other medications. ${ }^{20}$ Thus, there is clinical evidence for benefits of GH in the setting of SBS and CD. However, potential effects of $\mathrm{GH}$ on fibrosis, a serious complication of $C D$, have not been analyzed in the clinical studies or in animal models of inflammatory bowel disease (IBD).

Beneficial effects of $\mathrm{GH}$ on intestinal inflammation have been documented in animal models of colitis. Administration of rhGH reduced inflammation in the trinitrobenzene sulfonic acid rat model of IBD. ${ }^{21,22}$ Transgenic mice overexpressing $\mathrm{GH}$ exhibited improved mucosal repair after acute colitis induced by dextran sodium sulfate compared with wild-type mice. ${ }^{23} \mathrm{Im}$ proved repair in transgenic mice overexpressing $\mathrm{GH}$ was associated with more rapid but transient increases in crypt cell proliferation. However, $\mathrm{GH}$ action on intestinal fibrosis was not analyzed in any of these studies. Overall, fibrosis during chronic inflammation has been less well studied than inflammation. This reflects the fact that many animal models of IBD do not exhibit fibrosis and analyses in clinical trials generally are limited to the mucosa and not the submucosal layers, which are predominant sites of fibrosis. Concerns that GH treatment could exacerbate fibrosis stem from preliminary observations that GH stimulates collagen accumulation in cultured intestinal myofibroblasts, ${ }^{24}$ the primary mesenchymal cell type thought to mediate intestinal fibrosis. ${ }^{6} \mathrm{GH}$ also induces insulin-like growth factor-I (IGF-I) expression in some tissues and considerable evidence suggests that IGF-I may play a role in mediating fibrosis in CD. ${ }^{1}$ This raises the possibility that GH therapy in IBD patients may increase directly or indirectly intestinal collagen deposition or fibrosis. This study tested the hypothesis that therapeutically administered GH exacerbates fibrosis in a rat model of chronic intestinal inflammation induced by peptidoglycan-polysaccharide polymers derived from group A streptococci (PG-APS), one of the few animal models characterized by fibrosis associated with chronic intestinal inflammation. ${ }^{25}$ When injected subserosally into ileum and cecum of susceptible rat strains, PG-APS polymers induce acute inflammation for 24-48 hours followed by remission of inflammation and then spontaneous reactivation between 10-20 days after injection with progression to chronic granulomatous inflammation. ${ }^{26,27}$ This model particularly is relevant to $\mathrm{CD}$ for a number of reasons. Reactivation and chronic inflammation is T-cell mediated and accompanied by systemic responses including arthritis, which is also a complication in a significant number of $\mathrm{CD}$ patients. ${ }^{28}$ Importantly, chronic inflammation induced by PG-APS is known to involve severe transmural fibrosis and smooth muscle hyperplasia, ${ }^{25}$ making this model particularly useful for studying the possible effects of therapeutic interventions on fibrosis. In the present study, we tested whether GH given therapeutically after reactivation of chronic inflammation altered the severity of fibrosis associated with chronic PG-APS-induced enterocolitis. As well as testing the effects of $\mathrm{GH}$ on fibrosis, we examined whether $\mathrm{GH}$ altered the severity of intestinal inflammation, key cytokine mediators of inflammation, or local expression of IGF-I, which is upregulated at sites of fibrosis in the PG-APS model ${ }^{29}$ and in involved intestine of patients with CD.6,30,31 Our study provides evidence that $\mathrm{GH}$ improves rather than exacerbates intestinal fibrosis in the PG-APS model and that this is correlated with local induction of suppressor of cytokine signaling-3 (SOCS-3). SOCS-3 is a cytokineinducible signaling molecule that, to date, has been linked primarily to negative feedback regulation of cytokine action, particularly interleukin (IL)-6 action on macrophages and $\mathrm{T}$ cells. ${ }^{32,33}$ Given the unexpected antifibrogenic actions of $\mathrm{GH}$ and its induction of SOCS-3, follow-up studies were performed in intestinal myofibroblasts to examine directly whether GH induces SOCS-3 in intestinal mesenchymal cells and to test whether SOCS-3 negatively modulates the effects of GH or IGF-I on collagen accumulation. Increasing evidence suggests a role for tumor necrosis factor $\alpha$ (TNF $\alpha$ ) in inflammationinduced fibrosis in other organs including lung and kidney ${ }^{34,35}$ and that $\mathrm{TNF} \alpha$ is a key proinflammatory mediator in CD. ${ }^{28}$ Therefore, we tested whether SOCS-3 influenced $\mathrm{TNF} \alpha$ action on collagen accumulation in intestinal myofibroblasts.

\section{Materials and Methods}

\section{Bacterial Cell Wall Preparation}

PG-APS fragments from cell walls of group A, type 3, strain D58 streptococci (Streptococcus pyogenes) were isolated and prepared as previously described. ${ }^{36}$ The preparation was sonicated immediately before use to disperse aggregates. The final PG-APS concentration based on rhamnose measurements was $12 \mathrm{mg} / \mathrm{mL}$.

\section{Experimental Protocol}

Female inbred specific pathogen-free Lewis rats (140$170 \mathrm{~g}$ ) were obtained from Charles River Laboratories (Raleigh, NC). All animals were housed in standard cages with 6 animals per cage and were allowed food and water ad libitum. All animal procedures were approved by the Institutional Animal Care and Use Committee of the University of North Carolina at Chapel Hill and conformed to National Institutes of Health guidelines. Animals were anesthetized with $1.5 \mathrm{~mL} / \mathrm{kg}$ body weight Innovar (Pitman-Moore, Washington Crossing, NJ) and $80 \mathrm{mg} / \mathrm{kg}$ body weight ketamine hydrochloride, and their intestines were exposed 
by laparotomy using aseptic technique. A total of 24 rats were injected subserosally with PG-APS (12.5 $\mu \mathrm{g}$ rhamnose/g body weight) into 7 sites of the distal ileum and cecum. A control group of rats $(n=16)$ were injected with human serum albumin (HSA; $37.5 \mu \mathrm{g} / \mathrm{g}$ body weight, Baxter Healthcare Corporation, Glendale, CA). The rats were monitored for arthritis and were weighed daily. Of the 24 rats injected with PG-APS, 16 rats showed spontaneous reactivation of a chronic inflammatory response to PG-APS indicated by an increase in joint diameter of .6 $\mathrm{mm}$ from the previous measurement accompanied by edema and redness in 1 or both hind ankle joints. On the day of reactivation, rats were implanted with osmotic minipumps (Durect Corporation, Cupertino, CA) to administer $\mathrm{rhGH}(500 \mu \mathrm{g} / \mathrm{kg}$ body weight/day, Genentech Inc., San Francisco, CA) or vehicle (saline) for 14 days. The dose of $\mathrm{GH}$ was chosen to match the low doses reported in the literature for clinical trials in humans. ${ }^{17}$ This dose is at the low end of a range of doses of GH tested for effects on the intestine in rodent models. ${ }^{21,22,37,38}$ PG-APS-injected rats showing reactivation were paired based on comparable joint diameter at onset of reactivation and one of each pair was administered $\mathrm{GH}$ and the other was administered vehicle. The aim in pairing animals for comparable joint diameter was to minimize any potential effects of differences in disease severity at the onset of treatment. An experienced laboratory research analyst assigned the paired animals to vehicle or $\mathrm{GH}$ treatment groups and assigned a code number to each animal such that experimenters performing all subsequent analyses and evaluation or scoring of disease severity were blinded to the treatment groups. A total of 8 pairs of GH-treated and vehicle-treated PG-APS-injected rats were studied. HSA control rats were administered GH $(n=8)$ or vehicle $(n=8)$ in parallel with PG-APS-treated groups. Joint diameter and body weight were monitored daily throughout the experiment. After the 14-day treatment period, rats were killed by an intramuscular injection of sodium pentobarbital $(100 \mu \mathrm{g} / \mathrm{g}$ body weight, Abbot Laboratories, Chicago, IL). The abdomen was opened by a midline incision and a gross gut disease score was derived as one measure of disease severity. Well-established criteria for gross gut disease score have been detailed in previous reports using the PG-APS model. ${ }^{39}$ Briefly, 4 independent parameters consisting of extent of cecal wall thickening, severity of adhesions, severity of mesenteric contractions, and number of cecal nodules were each given a score ranging from 0 to 4 , where 4 indicates the most severe disease. The scores for each parameter were totaled to derive an overall gross gut disease score, with a maximum possible score of 16.39

\section{Sample Collection}

Blood was collected by cardiac puncture for hematologic assays (performed by the Animal Clinical Core Facility at the University of North Carolina). Plasma was separated by centrifugation and plasma IGF-I concentrations were measured by enzyme-linked immunosorbent assay (Diagnostic Systems Laboratories Inc., Webster, TX). Samples were pretreated as described in the enzyme-linked immunosorbent assay protocol to remove IGF-binding proteins complexed to IGF-I. Briefly, enzyme-linked immunosorbent assay samples were incubated with biotin-labeled rat IGF-I and goat anti-rat IGF-I antiserum in wells coated with rabbit anti-goat $\gamma$ globulin. Unlabeled IGF-I in plasma and biotin-labeled IGF-I compete for limited anti-rat IGF-I binding sites. Streptavidin-horseradish peroxidase binds the antibody-free biotinylated rat IGF-I, whose concentration in standards and each sample is estimated based on enzymatic turnover of the substrate tetramethylbenzidine and absorbance at 450 and $620 \mathrm{~nm}$.

The entire cecum was dissected and the contents were flushed with ice-cold .9\% saline. The cecal tip was embedded in frozen tissue-embedding medium (Fisher Scientific, Fair Lawn, NJ) for in situ hybridization histochemistry. Adjacent samples were formalin-fixed and paraffin-embedded; sections were used for histologic evaluation of inflammation and fibrosis. The remaining cecum was cut longitudinally into 2 portions and homogenized immediately in $4 \mathrm{~mol} / \mathrm{L}$ guanidine thiocyanate for RNA extraction or in protein extraction buffer (50 mmol/L Hepes, $150 \mathrm{mmol} / \mathrm{L} \mathrm{NaCl}, 20 \mathrm{mmol} / \mathrm{L} \mathrm{Na}$ pyrophosphate, $100 \mathrm{mmol} / \mathrm{L} \mathrm{NaF}, 1.5 \%$ Triton X-100, and 100 $\mathrm{mmol} / \mathrm{L}$ ethylenediaminetetraacetic acid containing protease inhibitors: $1 \mu \mathrm{g} / \mathrm{mL}$ aprotinin, $1 \mathrm{mmol} / \mathrm{L}$ phenylmethylsulfonyl fluoride, and $2 \mathrm{mmol} / \mathrm{L}$ vanadate; $\mathrm{pH} 7.4$ ).

\section{Histologic Scoring of Inflammation and Fibrosis}

Coded paraffin-embedded, formalin-fixed sections of cecum were stained with $\mathrm{H} \& \mathrm{E}$, Masson's trichrome, or Sirius red. H\&E-stained sections were used to obtain a histologic score for inflammation using criteria previously described. ${ }^{27,39}$ A score ranging from 0 to 4 ( 4 being the most severe) was assigned for both acute and chronic inflammation of each layer of the cecal wall. The acute and chronic scores were summed to derive an overall inflammatory score for each rat, and the maximum possible score was 32 . The acute inflammatory score was based on hemorrhage, edema, polymorphonuclear leukocytic infiltration, and necrosis. The chronic inflammatory score was based on the number of mononuclear cells present.

Masson's trichrome- and Sirius red-stained sections of cecum were used to obtain a histologic score for fibrosis. Masson's trichrome stains collagen, whereas Sirius red stains only fibrillar collagen. Experimental sections were compared with sections from normal untreated control rats to derive a score ranging from 0 to 5 for increases in collagen deposition where 0 represents no increase and $1-5$ represent a progressive increase in collagen in different layers of the cecal wall (Table 1). A score of 5 is the most severe fibrosis representing increased collagen deposition throughout all layers from mucosa to serosa (Table 1 ). The fibrosis score was multiplied by $1-4$ to reflect $0 \%-100 \%$ extent of the section exhibiting fibrosis. At least 2 sections of cecum per animal were scored.

\section{Total RNA Extraction and Northern Blot Hybridization Assays}

Total RNA was prepared by the guanidine thiocyanate, cesium chloride procedure as previously described. ${ }^{29}$ Northern blot hybridization was performed as previously de- 
Table 1. Criteria for Histologic Fibrosis Score of Intestine

\begin{tabular}{|c|c|c|}
\hline & Score & Description \\
\hline \multirow[t]{6}{*}{ Fibrosis } & 0 & No increased collagen deposition \\
\hline & 1 & $\begin{array}{l}\text { Increased collagen deposition in } \\
\text { submucosa }\end{array}$ \\
\hline & 2 & $\begin{array}{l}\text { Increased collagen deposition in } \\
\text { submucosa and mucosa }\end{array}$ \\
\hline & 3 & $\begin{array}{l}\text { Increased collagen deposition in } \\
\text { muscularis mucosa, } \\
\text { submucosa, and mucosa; } \\
\text { thickening, disorganization of } \\
\text { the muscularis mucosa }\end{array}$ \\
\hline & 4 & $\begin{array}{l}\text { Increased collagen deposition in } \\
\text { muscularis propria, muscularis } \\
\text { mucosa, submucosa, and } \\
\text { mucosa }\end{array}$ \\
\hline & 5 & $\begin{array}{l}\text { Increased collagen deposition } \\
\text { throughout all layers including } \\
\text { serosa }\end{array}$ \\
\hline \multirow[t]{4}{*}{ Percent involvement } & 1 & $0-25 \%$ of section \\
\hline & 2 & $25-50 \%$ of section \\
\hline & 3 & $50-75 \%$ of section \\
\hline & 4 & $75-100 \%$ of section \\
\hline
\end{tabular}

scribed ${ }^{40}$ using ${ }^{32} \mathrm{P}$-deoxycytidine triphosphate-labeled complementary DNA probes (Random Primed DNA Labeling Kit; Roche Diagnostics Corporation, Indianapolis, IN) specific for rat procollagen $\alpha 1(\mathrm{I})^{25}$, rat $\mathrm{TNF} \alpha$ (a generous gift of $\mathrm{Dr}$ Karl Decker, University of Freiburg, Freiburg, Germany), and mouse SOCS-3 (a generous gift of Dr Douglas Hilton, The Walter and Eliza Hall Institute of Medical Research, Victoria, Australia). ${ }^{32} \mathrm{P}$-uridine triphosphate-labeled mouse IL-1 $\beta$ and rat IGF-I antisense RNAs also were used as probes. ${ }^{41}$ To account for minor variations in RNA loading across samples, blots were reprobed for rat glyceraldehyde-3-phosphate dehydrogenase (GAPDH) messenger RNA (mRNA) by using an antisense RNA probe prepared from a commercially available DNA template (Ambion Inc., Austin, TX). Blots were scanned on a Molecular Dynamics Storm 840 Phosphorimager and mRNA abundance was quantified using Image Quant software (version 1.2) for Macintosh (Amersham Biosciences, Piscataway, NJ). The abundance of each test mRNA was normalized to the abundance of GAPDH mRNA in each sample.

\section{Western Immunoblot and Immunoprecipitation}

A total of $100 \mu \mathrm{g}$ cecal protein extracts were separated in $7.5 \%$ polyacrylamide reducing gels followed by semidry transfer onto polyvinylidene difluoride membranes (Millipore, Billerica, MA) and blocked in $.1 \%$ casein and $.2 \times$ phosphatebuffered saline. Blots then were immunoblotted with a rabbit antibody specific for procollagen $\alpha 1$ (I) (Rockland, Gilbertsville, PA) and incubated with a goat anti-rabbit secondary antibody conjugated to an infrared dye (IR Dye 800 Conjugated Goat Anti-Rabbit IgG; Rockland) at a 1:5000 dilution and signal visualized using the Odyssey Infrared Imaging System (Li-Cor Biosciences, Lincoln, NE). The infrared-conjugated secondary antibody allows detection of signal without using the chemiluminescence detection method. Instead, the Odyssey System uses excitatory lasers, enabling fluorescence detection of the infrared-labeled secondary antibody. The benefits of using the Odyssey system vs chemiluminescence include detection of proteins across a wide linear range without the limitation of enzyme/substrate kinetics and greater sensitivity. The signal was quantified using the Odyssey Infrared Imaging System Application software version 1.2 (Li-Cor Biosciences). Subsequent blotting with actin antibody (Sigma, St. Louis, MO) was performed to control for differences in protein loading.

SOCS-3 was immunoprecipitated from $500 \mu \mathrm{g}$ cecal protein extracts with $1 \mu \mathrm{g}$ goat anti-SOCS-3 antibody (Santa Cruz Biotechnology, Santa Cruz, CA) and $20 \mu \mathrm{L} 50 \%$ protein G agarose beads (Sigma). Nonspecific proteins were removed by washing 2 times in cold protein extraction buffer. The samples were heated in Promega (Madison, WI) $2 \times$ loading buffer at $100^{\circ} \mathrm{C}$ for 5 minutes and separated in $12.5 \%$ polyacrylamide reducing gels followed by semidry transfer onto polyvinylidene difluoride membranes. Membranes were blocked in .1\% casein and $.2 \times$ phosphate-buffered saline and immunoblotted with a rabbit anti-SOCS-3 antibody (a generous gift of Dr Douglas Hilton). Blots then were incubated with the goat anti-rabbit secondary antibody conjugated to an infrared dye and signal visualized using the Odyssey Infrared Imaging System. Immunoprecipitation followed by Western immunoblotting for SOCS-3 was performed because Western immunoblotting alone lacked the sensitivity needed to detect SOCS- 3 in cecal protein extracts. Complete SOCS-3 recovery was ensured by follow-up immunoprecipitation of the cecal extracts with additional primary antibody and Western analysis.

\section{In Situ Hybridization Histochemistry}

Antisense and sense SOCS-3 RNA probes were generated by polymerase chain reaction using primers described by Rosell et al, ${ }^{42}$ with the addition of a T7 RNA polymerase site $5^{\prime}$ to the antisense primer and a SP6 RNA polymerase site 5' to the sense primer. Polymerase chain reaction products were used as a complementary DNA template to generate ${ }^{35} \mathrm{~S}$ uridine triphosphate-labeled sense and antisense RNA probes using either SP6 or T7 RNA polymerases, respectively. In situ hybridization was performed on $10-\mu \mathrm{m}$ cryostat sections of cecum that were processed as previously described ${ }^{6}$ with some modifications. Briefly, frozen sections were fixed in $4 \%$ paraformaldehyde, treated with proteinase $\mathrm{K}(.5 \mu \mathrm{g} / \mathrm{mL})$, and acetylated with triethanolamine $(.1 \mathrm{~mol} / \mathrm{L})$ and $.25 \%(\mathrm{vol} / \mathrm{vol})$ acetic anhydride. Sections were prehybridized for 1 hour at $62^{\circ} \mathrm{C}$ in hybridization buffer containing $75 \%$ formamide. Sections were hybridized with ${ }^{35} \mathrm{~S}$ - uridine triphosphate-labeled probes in hybridization buffer for 18 hours at $62^{\circ} \mathrm{C}$ in a humidified chamber, treated with $\mathrm{RNase}$, and washed in lowsalt buffers at $62^{\circ} \mathrm{C}$. Slides were exposed to NTB-2 emulsion (Kodak, Rochester, NY) for 14 days at $4^{\circ} \mathrm{C}$, developed with D-19 developer (Kodak) and counterstained with hematoxylin. Sections were photographed under dark- and bright-field illu- 
mination. Adjacent sections were stained with Sirius red to localize collagen and $\mathrm{H} \& \mathrm{E}$ for histology.

\section{In Vitro Analyses}

Mouse intestinal myofibroblasts were used to evaluate directly the effect of GH, IGF-I, and TNF $\alpha$ on collagen accumulation and the possible modulation of their actions by overexpression of SOCS-3. Mouse, rather than rat, intestinal myofibroblasts were used because mouse-derived cells have proved easier to transfect. Methods for preparation of early passage cultures of mouse intestinal myofibroblasts were modified from previously described methods used to isolate rat intestinal myofibroblasts. ${ }^{25}$ Briefly, adult (40- to 50-day old) mice were killed and the ileum was dissected and washed in Dulbecco's modified essential medium plus antibiotics (100 $\mathrm{U} / \mathrm{mL}$ penicillin and $50 \mu \mathrm{g} / \mathrm{mL}$ streptomycin). Whole-tissue pieces were washed repeatedly by pipetting into suspension and collection by centrifugation. After the final wash, the tissue pieces were resuspended in $5 \mathrm{~mL}$ Dulbecco's modified essential medium plus collagenase $(300 \mathrm{U} / \mathrm{mL}$ CLS-1; Worthington, Lakewood, NJ) and dispase $(.1 \mathrm{mg} / \mathrm{mL}$; Roche Diagnostics Corporation) and placed on an orbital shaker (80 cycles/ min) for 25 minutes at room temperature. Two volumes of Dulbecco's modified essential medium plus $10 \%$ fetal bovine serum then were added and the cell slurry was dispersed by vigorous pipetting. The cell slurry was allowed to settle and the supernatant was collected and centrifuged. The supernatant was discarded and the cell pellet was washed in Dulbecco's modified essential medium plus $10 \%$ fetal bovine serum and plated into a T-75 tissue culture flask in the same medium. Medium was changed after 48 hours to remove nonadherent/ dead cells. Adherent cells were maintained in medium plus $10 \%$ fetal bovine serum with media changes biweekly. Myofibroblast phenotype was confirmed based on positive expression for vimentin and $\alpha$-smooth muscle actin as evaluated by Western immunoblot. ${ }^{25,43}$ Subconfluent cells were studied at passages $3-8$.

Intestinal myofibroblasts were serum deprived and treated with $\mathrm{GH}\left(10^{-9} \mathrm{~mol} / \mathrm{L}\right)$, TNF $\alpha(1 \mathrm{ng} / \mathrm{mL})$, IL-6 (10 ng/mL), IL-10 $(10 \mathrm{ng} / \mathrm{mL})$, or PG-APS $(20 \mu \mathrm{g} / \mathrm{mL})$ alone or in combination with GH for 60 minutes. Doses of GH and PG-APS were based on maximal responses found by a dose response (data not shown). Doses of TNF $\alpha$, IL-6, and IL-10 were based on maximal doses reported in other studies and the duration was chosen based on the time course of SOCS-3 induction by GH or IL-6 in other cell types. ${ }^{44-46}$ Total RNA was extracted using TRIzol Reagent (Invitrogen, Carlsbad, CA). SOCS-3 mRNA abundance was determined by Northern blot hybridization as described earlier.

We previously have reported direct effects of GH and IGF-I to stimulate collagen accumulation in cultured intestinal myofibroblasts. ${ }^{24}$ In the present study, intestinal myofibroblasts were transfected with a human pBIG2i-FLAGSOCS-3 expression vector or empty vector provided by Dr Richard Furlanetto (University of Rochester School of Medicine and Dentistry, New York, NY). pBIG2i-FLAGSOCS-3 contains the complete coding sequence of human SOCS-3 with a FLAG-tag epitope at the amino terminus. The empty vector is identical except that it lacks the inserted SOCS- 3 coding sequence. Both vectors were purified by using an endotoxin-free plasmid kit (Qiagen, Valencia, CA). Cells were transfected with empty vector or pBIG2i-FLAGSOCS-3 using Effectene transfection reagent (Qiagen) and selected continuously with media containing $100 \mu \mathrm{g} / \mathrm{mL}$ Hygromycin B (Roche). Stable transfectants maintained their myofibroblast phenotype, as indicated by positive expression for vimentin and $\alpha$-smooth muscle actin. Transfected cells were serum deprived and treated with rhGH $\left(10^{-10} \mathrm{~mol} / \mathrm{L}\right)$, human IGF-I $(20 \mathrm{ng} / \mathrm{mL})$, or mouse TNF $\alpha(1 \mathrm{ng} / \mathrm{mL})$ and compared with no-treatment control cells. TNF $\alpha$ was tested as well as IGF-I because of increasing evidence for profibrogenic actions of TNF $\alpha$ in animal models of inflammation-induced fibrosis of other organs ${ }^{34,35}$ and because of the established role of $\mathrm{TNF} \alpha$ as a proinflammatory mediator in $\mathrm{CD}^{28}$ and the PG-APS model. Reverse-transcription polymerase chain reaction verified overexpression of SOCS-3 in myofibroblasts transfected with the SOCS-3 expression vector (data not shown). Collagen accumulation in total cell lysates was determined by Western immunoblot. Cells were solubilized in sodium dodecyl sulfate sample buffer and size fractionated on $8.5 \%$ sodium dodecyl sulfate-polyacrylamide gels and transferred onto polyvinylidene difluoride membranes (Millipore). Blots were blocked in phosphate-buffered saline containing $3 \%$ nonfat dry milk and incubated for 16 hours at $4^{\circ} \mathrm{C}$ with a rabbit polyclonal antibody specific for procollagen $\alpha 1(\mathrm{I})$ (Rockland). Blots were washed and then exposed to peroxidase-conjugated secondary antibody for 1 hour at room temperature. Blots were washed and immunoreactive proteins were detected by using an enhanced chemiluminescence detection system (Amersham, Piscataway, NJ). Blots were reprobed with rabbit polyclonal anti-actin as a loading control (Sigma). Radiograph films were analyzed by densitometry and signal intensity for procollagen $\alpha 1(\mathrm{I})$, or loading control was quantified using National Institutes of Health image software (version 1.61; available at: http://rsb. info.nih.gov/nih-image/).

\section{Statistical Analyses}

Values are expressed as mean \pm SEM. Data from in vivo experiments were analyzed by 2 -way analysis of variance to test for significant effects of PG-APS or GH, and a significant interaction between PG-APS and GH, which provides statistical evidence for an effect of $\mathrm{GH}$ on the response to PG-APS. Subsequent pair-wise comparisons used Tukey's post hoc test to test for significant differences between 2 particular groups. Linear regression analyses were performed to test for possible correlations between particular parameters measured Data from in vitro experiments were compared by 1-way analysis of variance for significant effects of treatments vs control followed by planned pairwise comparisons. A $P$ value $<.05$ was considered statistically significant in all analyses. 


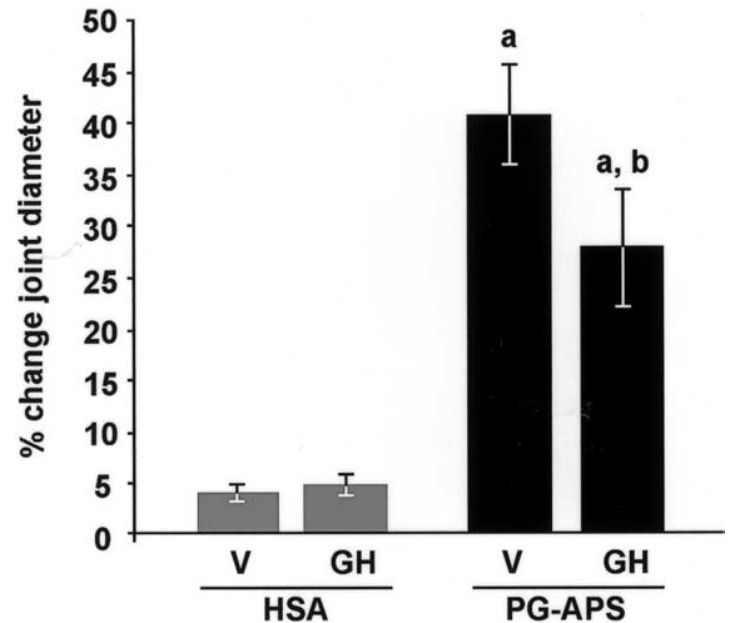

Figure 1. Mean percent change in joint diameter during GH or vehicle infusion in HSA- and PG-APS-injected rats. Values are mean \pm SEM of percent joint diameter change in each animal after 14 days of infusion with $\mathrm{GH}$ or vehicle relative to diameter at the start of $\mathrm{GH}$ or vehicle (v) infusion. ${ }^{a} P<.005$ vs HSA controls; ${ }^{b} P<.05$ vs PG-APS + V.

\section{Results}

\section{GH Reduces Gross Intestinal Injury and Joint Inflammation During PG-APS-Induced Colitis}

We previously established that increased joint diameter provides a reliable and readily measurable sign of reactivation and progression of chronic inflammation and enterocolitis in the PG-APS model. ${ }^{26}$ In this study, the diameter of both hind ankle joints was measured daily to monitor reactivation and as an overt measure of disease severity over the course of $\mathrm{GH}$ or vehicle treatment. Joint diameter at the onset of reactivation in PG-APS-injected rats was comparable in animals assigned to GH (15.26 $\pm .38 \mathrm{~mm}$, pooled left and right joints) or vehicle $(15.45 \pm .35 \mathrm{~mm})$ treatment groups and was significantly higher than in control animals injected with HSA and assigned to vehicle (13.32 \pm .16 $\mathrm{mm})$ or $\mathrm{GH}(13.08 \pm .15 \mathrm{~mm} ; P<.05)$ groups. Figure 1 shows the mean percentage change in joint diameter from start of vehicle or $\mathrm{GH}$ infusion to the end of the 14-day infusion period. HSA control animals showed no signs of inflammation or redness and only small increases in joint diameter, which are typical of normal growth, and did not differ significantly between vehicle- and GH-treated rats over the course of the 14-day treatment (Figure 1). PG-APS-injected rats showed significant increases in joint diameter typical of the worsening joint inflammation as chronic inflammation progressed. PGAPS-injected animals given GH showed significantly smaller increases in joint diameter compared with vehicle-treated PG-APS-injected animals (Figure 1).
Body weight, white blood cell count, and hemoglobin concentration were used as clinical measures of disease (Table 2). As a group, HSA-injected rats gained more weight than PG-APS-injected rats during the 14-day infusion period $(7.6 \% \pm 1.5 \%$ HSA combined vehicle and $\mathrm{GH}$ vs $2.1 \% \pm 1.5 \%$ PG-APS; $P<.05)$. When separated into vehicle or $\mathrm{GH}$ treatment groups, $\mathrm{GH}$ did not significantly increase body weight gain in either HSA- or PG-APS-injected rats compared with vehicle (Table 2). PG-APS-injected rats showed increased white blood cell counts and reduced hemoglobin concentrations, which are typical signs of disease in this model, ${ }^{39}$ and GH did not alter these measures of inflammation.

HSA control rats given vehicle or GH had little or no gross evidence of intestinal injury, as indicated by low gross gut disease scores (Table 3). PG-APS rats showed extensive adhesions, mesentery contractions, cecal wall thickening, cecal nodules, and hepatic nodules (Table 3). PG-APS rats administered GH had small but significant reductions in gross disease score compared with PGAPS-injected rats given vehicle (Table 3). Significantly lower mean scores for adhesions and mesentery contractions, which are 2 complications of intestinal fibrosis, primarily contributed to the lower gross injury scores in GH-treated PG-APS-injected rats (Table 3).

\section{Modest Reductions in Histologic and Biochemical Measures of Fibrosis in GH-Treated Rats}

Bright-field photomicrographs of representative cecum sections stained with Sirius red for collagen are shown in Figure 2. Mean, blinded histologic scores for severity of fibrosis in cecum sections stained with Sirius red or Masson's trichrome are shown in Table 4. HSA control rats treated with vehicle or GH had low fibrosis scores $(<1.0)$ with the majority of collagen deposition located within the submucosa, as is found in the normal cecum (Figures $2 A$ and $B$ ). PG-APS rats showed obvious

Table 2. Percent Body Weight Change and Hematologic Profile in Rats Injected With PG-APS or HSA and Given GH or Vehicle

\begin{tabular}{lccc}
\hline & $\begin{array}{c}\text { \% Increase body } \\
\text { weight }\end{array}$ & $\begin{array}{c}\text { WBC } \\
\left(\times 10^{3} / \mathrm{mL}\right)\end{array}$ & $\begin{array}{c}\text { Hemoglobin } \\
(\mathrm{g} / \mathrm{dL})\end{array}$ \\
\hline HSA + V & $6.7 \pm 1.4$ & $5.2 \pm .4$ & $16.5 \pm .2$ \\
HSA + GH & $8.3 \pm 1.3$ & $7.4 \pm 1.1$ & $15.5 \pm .8$ \\
PG-APS + V & $1.4 \pm 1.8^{b}$ & $19.3 \pm 1.9^{a}$ & $13.4 \pm .3^{b}$ \\
PG-APS + GH & $2.8 \pm 2.4$ & $17.9 \pm 1.9^{a}$ & $12.6 \pm .6^{a}$ \\
\hline
\end{tabular}

NOTE. Values are expressed as mean \pm SEM. $n=8$ animals in each treatment group.

WBC, white blood cells; $V$, vehicle.

${ }^{a} P<.001$ vs HSA controls.

${ }^{b} P<.05$ vs HSA controls. 
Table 3. Gross Findings of Rats Injected With HSA or PG-APS and Administered Vehicle or GH

\begin{tabular}{lcccccc}
\hline & Gross injury score & Adhesions & $\begin{array}{c}\text { Mesentery } \\
\text { contractions }\end{array}$ & $\begin{array}{c}\text { Cecal-wall } \\
\text { thickening }\end{array}$ & Cecal nodules & Liver nodules \\
\hline HSA + V & $.2 \pm .2$ & $.1 \pm .1$ & $.1 \pm .1$ & $.0 \pm .0$ & $.0 \pm .0$ & $.0 \pm .0$ \\
HSA + GH & $.1 \pm .1$ & $.1 \pm .1$ & $.0 \pm .0$ & $.0 \pm .0$ & $.0 \pm .0$ & $.0 \pm .0$ \\
PG-APS + V & $10.0 \pm .9^{a}$ & $2.9 \pm .4^{a}$ & $3.0 \pm .3^{a}$ & $2.1 \pm .2^{a}$ & $2.0 \pm .3^{a}$ & $2.5 \pm .4^{a}$ \\
PG-APS + GH & $8.0 \pm .4^{\mathrm{a}, b}$ & $1.7 \pm .3^{\mathrm{a}, c}$ & $2.1 \pm .4^{\mathrm{a}, b}$ & $1.9 \pm .1^{a}$ & $2.2 \pm .3^{a}$ & $1.7 \pm .3^{a}$ \\
\hline
\end{tabular}

NOTE. Values are expressed as mean \pm SEM. $n=8$ animals in each treatment group.

$\mathrm{V}$, vehicle.

$a P<.001$ vs HSA controls.

${ }^{b} P<.05$ vs PG-APS + V.

${ }^{c} P<.01$ vs PG-APS $+\mathrm{V}$.

increases in transmural collagen deposition (Figures $2 \mathrm{C}-$ $F)$, validated by significant increases in mean histologic scores for fibrosis (Table 4). PG-APS rats treated with GH had a modest but significant reduction in histologic scores for fibrosis (Table 4) compared with PG-APSinjected rats given vehicle (Table 4 ), as shown also by the representative sections in Figures $2 C$ and $E$ vs Figure $2 D$ and $F$.

Expression of procollagen $\alpha 1(\mathrm{I}) \mathrm{mRNA}$ and protein in cecal extracts were assayed as biochemical markers of fibrosis. GH had no effect on collagen mRNA or protein abundance in HSA control rats. However, during PG-
Vehicle

A

HSA

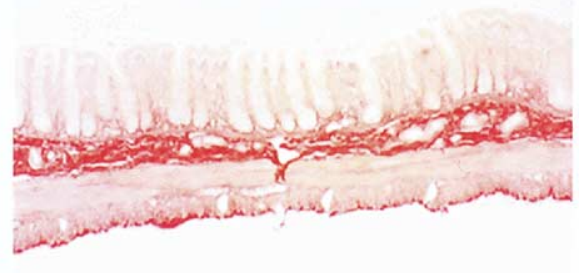

PG-APS

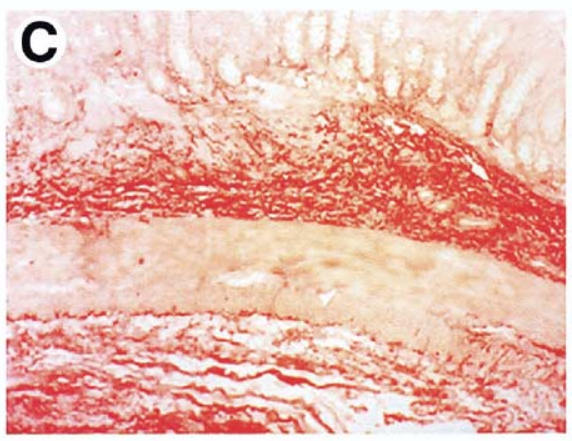

PG-APS

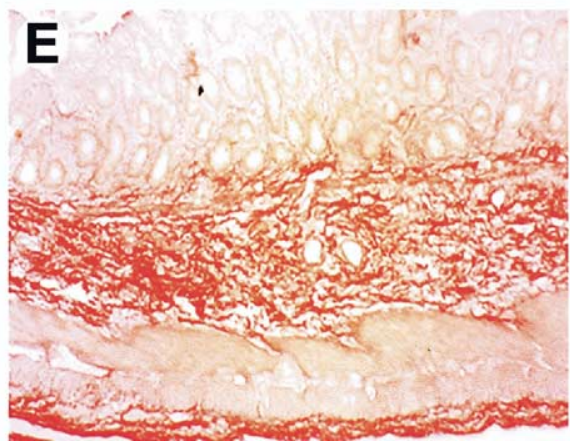

GH
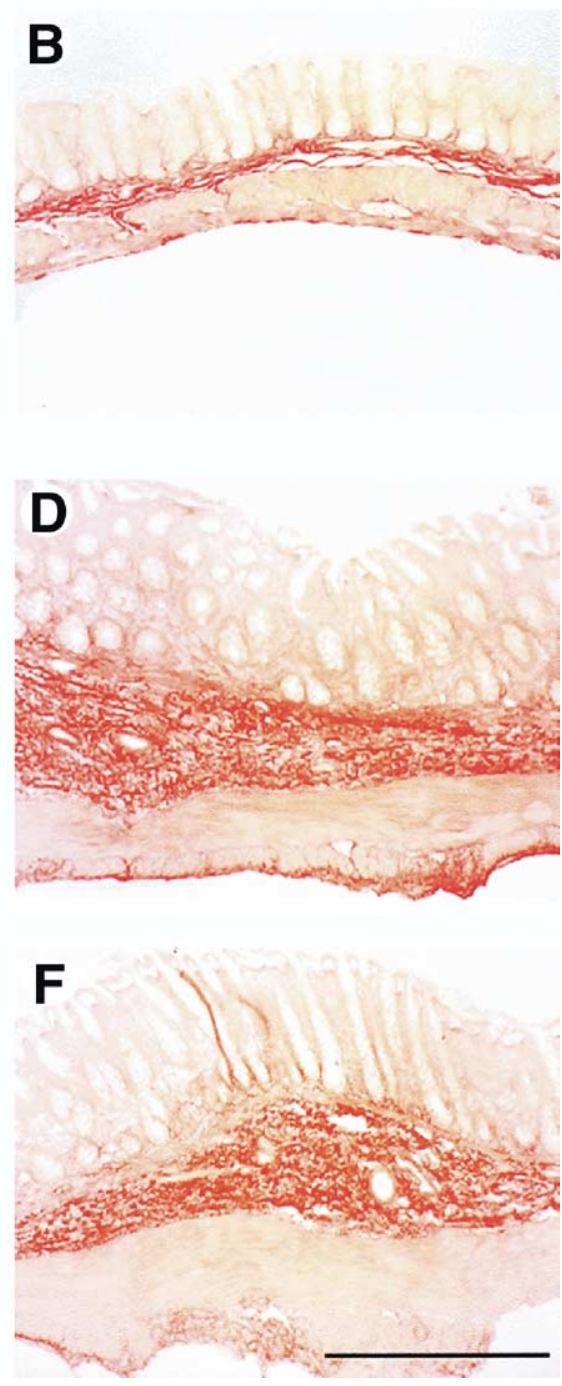

Figure 2. Representative brightfield photomicrographs of sections of cecum stained with Sirius red for collagen. (A) HSA + vehicle; $(B) \mathrm{HSA}+\mathrm{GH} ;(C, E)$ PG-APS + vehicle; $(D, F)$ PG-APS $+\mathrm{GH} .(F)$ Bar $=500 \mu \mathrm{m}$. 
Table 4. Fibrosis Scoring of Rat Cecum Injected With HSA or PG-APS and Administered Vehicle or GH

\begin{tabular}{lc}
\hline & Fibrosis score \\
\hline HSA + V & $.3 \pm .1$ \\
HSA + GH & $.7 \pm .2$ \\
PG-APS + V & $9.7 \pm .5^{a}$ \\
PG-APS + GH & $7.9 \pm .5^{\mathrm{a}, b}$ \\
\hline
\end{tabular}

NOTE. Values are expressed as mean \pm SEM. $n=8$ animals in each treatment group. Scores reflect evaluation of 4 sections of cecum for each animal.

$\mathrm{V}$, vehicle.

ap $<.001$ vs HSA controls.

${ }^{b} P<.05$ vs PG-APS + V

APS-induced colitis, GH modestly reduced collagen mRNA (Figure $3 A$ ) and protein (Figure $3 B$ ) abundance compared with vehicle control rats. Regression analysis revealed highly significant correlations in individual animals across the independent measures of fibrosis, indicating consistent results: cecal collagen mRNA vs histologic fibrosis scores $(r=.66 ; P<.01)$, cecal collagen mRNA vs cecal collagen protein $(r=.70 ; P<.005)$, cecal collagen protein vs histologic fibrosis scores $(r=$ $.51 ; P<.05)$.
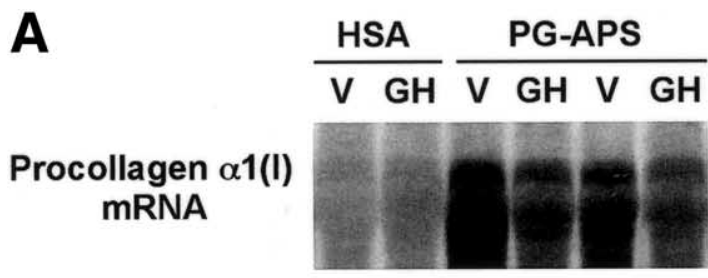

GAPDH mRNA
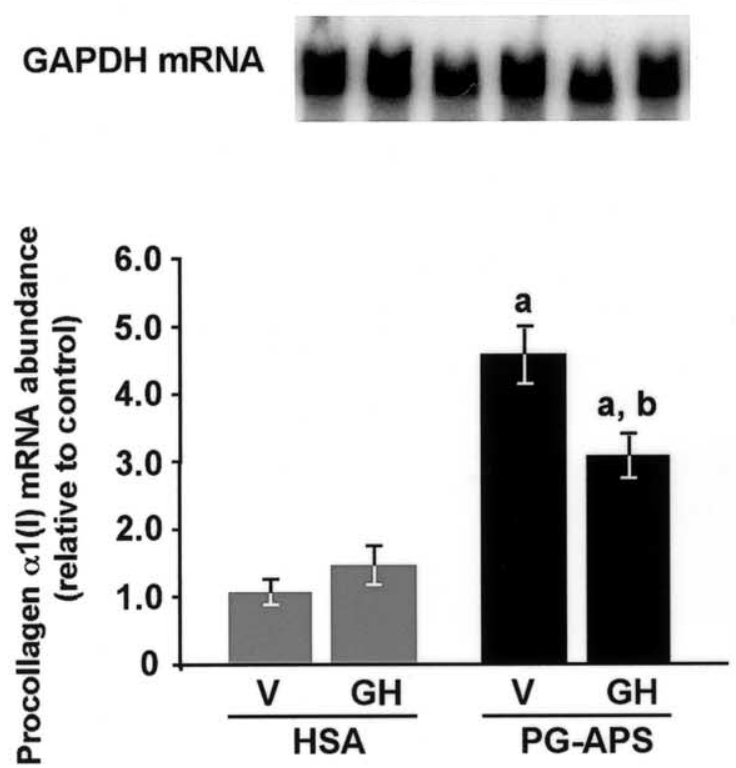

\section{GH Treatment Does Not Affect Severity of Inflammation in the Cecum}

To determine if effects of $\mathrm{GH}$ on fibrosis were associated with effects on intestinal inflammation, severity of colitis in the cecum was measured by an established blinded scoring system for acute and chronic inflammation. ${ }^{27,39}$ PG-APS-injected rats showed dramatic increases in scores for acute and chronic intestinal inflammation compared with HSA controls (Table 5). GH treatment had no significant effect on acute or chronic inflammation scores in either HSA- or PG-APS-injected rats (Table 5).

Expression of IL- $1 \beta$ and TNF $\alpha$ mRNA, two proinflammatory cytokines known to be up-regulated at the mRNA level in the PG-APS model, also were quantified as independent biochemical markers of inflammation. Figure 4 shows representative Northern blots of IL-1 $\beta$ and TNF $\alpha$ mRNA expression in the cecum of HSA and PG-APS rats treated with vehicle or GH. PG-APS-injected rats had significantly increased levels of cecal IL-1 $\beta$ and TNF $\alpha$ mRNAs. GH treatment had no significant effect on IL- $1 \beta$ or TNF $\alpha$ mRNA abundance in cecum of PG-APS-injected rats. Histo-
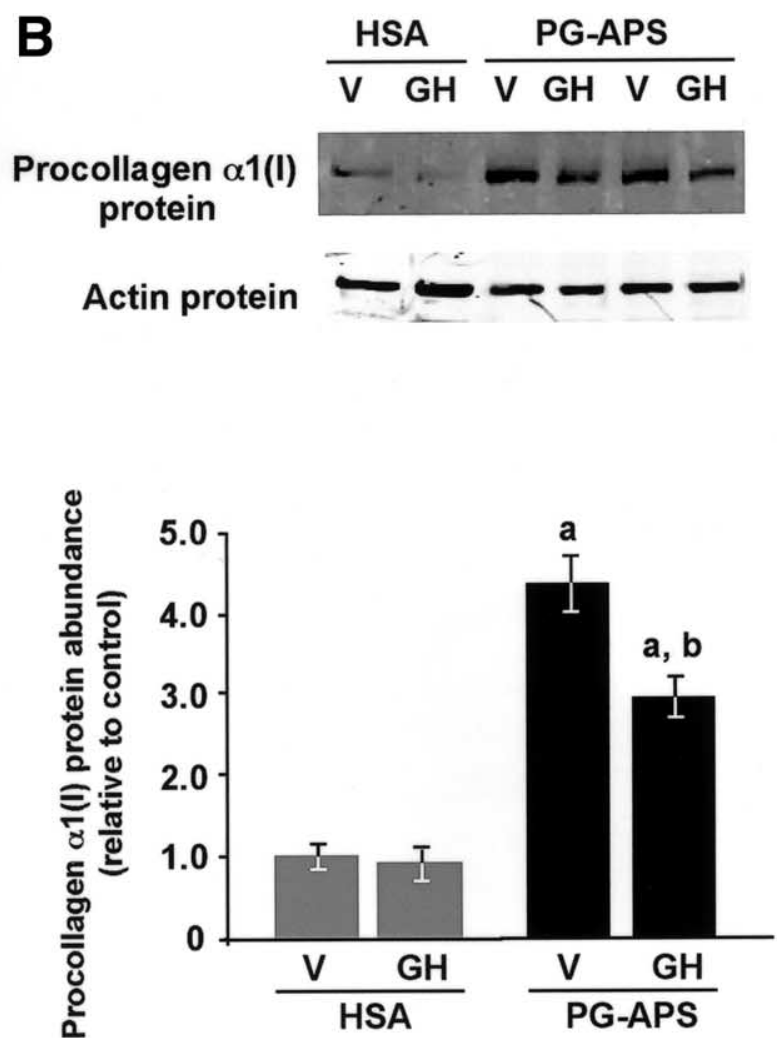

Figure 3. (A) Representative Northern blots showing procollagen $\alpha 1(\mathrm{I})$ and control (GAPDH) mRNA abundance in total RNA isolated from cecum and $(B)$ representative Western immunoblots for procollagen $\alpha 1(\mathrm{I})$ protein and actin protein as a loading control in cecal protein extracts. Treatments are indicated. Histograms showing mean \pm SEM of the fold-difference relative to the mean value of HSA + vehicle controls analyzed on the same blot. ${ }^{a} P<.005$ vs HSA controls, ${ }^{b} P<.05$ vs PG-APS + V. 
Table 5. Histologic Scoring of Inflammation in Cecum Sections Stained With H\&E From Rats Injected $\mathrm{GH}$

\begin{tabular}{lccc}
\hline & $\begin{array}{c}\text { Total } \\
\text { inflammation } \\
\text { score }\end{array}$ & $\begin{array}{c}\text { Acute } \\
\text { inflammation } \\
\text { score }\end{array}$ & $\begin{array}{c}\text { Chronic } \\
\text { inflammation } \\
\text { score }\end{array}$ \\
\hline HSA + V & $.8 \pm .2$ & $.0 \pm .0$ & $.8 \pm .2$ \\
HSA + GH & $.9 \pm .4$ & $.0 \pm .0$ & $.9 \pm .4$ \\
PG-APS + V & $9.1 \pm .9^{a}$ & $2.2 \pm .5^{a}$ & $6.7 \pm .3^{a}$ \\
PG-APS + GH & $9.7 \pm .8^{a}$ & $3.1 \pm .6^{a}$ & $6.9 \pm .3^{a}$ \\
\hline
\end{tabular}

NOTE. Values are expressed as mean \pm SEM. $n=8$ animals in each treatment group. Scores reflect evaluation of 2 sections of cecum for each animal.

$\mathrm{V}$, vehicle.

${ }^{a} P<.001$ vs HSA controls.

logic inflammatory scores were correlated directly with IL-1 $\beta$ expression $(r=.47 ; P<.05)$ and TNF $\alpha$ expression $(r=.51 ; P<.05)$ in individual animals, indicating consistent results from independent histologic and biochemical measures.
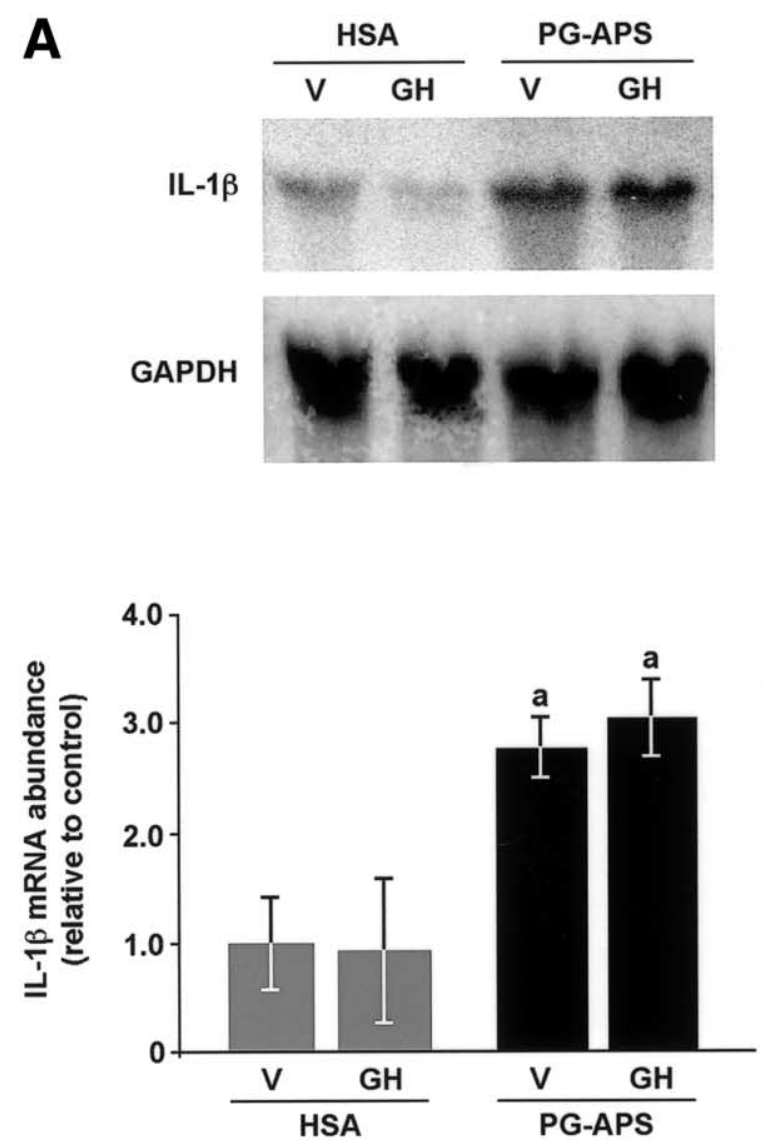
With HSA or PG-APS and Administered Vehicle or

Table 6. Concentration of Plasma IGF-I in Rats Injected With HSA or PG-APS Followed by Treatment With Vehicle or $\mathrm{GH}$

\begin{tabular}{lc}
\hline & Plasma IGF-I $(\mathrm{ng} / \mathrm{mL})$ \\
\hline HSA + V & $1102.9 \pm 49.2$ \\
HSA + GH & $1063.6 \pm 50.3$ \\
PG-APS + V & $1550.3 \pm 97.0^{a}$ \\
PG-APS + GH & $1405.5 \pm 50.8^{a}$ \\
\hline
\end{tabular}

NOTE. Values are expressed as mean \pm SEM. $n=8$ animals in each treatment group, performed in duplicate. $\mathrm{V}$, vehicle. ${ }^{a} P<.05$ vs HSA controls.

\section{Plasma Levels of IGF-I and Cecal Expression of IGF-I}

Because many actions of $\mathrm{GH}$ are mediated by IGF-I, plasma IGF-I and local IGF-I expression in the cecum were measured to determine if the effects of $\mathrm{GH}$ on fibrosis or joint diameter were related to altered IGF-I. Plasma IGF-I concentration was increased significantly by approximately $50 \%$ during PG-APS-induced inflammation compared with controls (Table 6). GH treatment caused no further increase in plasma IGF-I
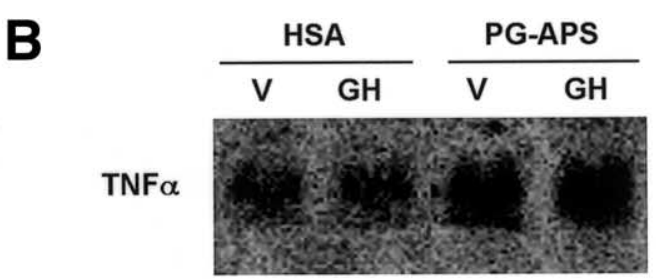

GAPDH
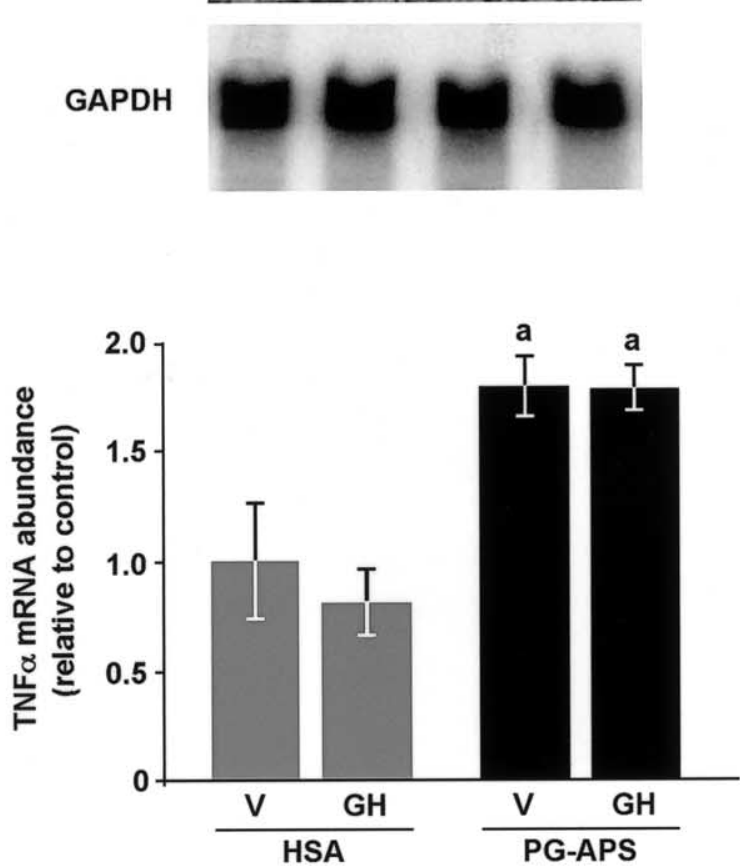

Figure 4. Representative Northern blots showing $(A) \mathrm{IL}-1 \beta$ and $(B) \mathrm{TNF} \alpha$ and control (GAPDH) mRNA expression in cecums of HSA- or PG-APS-injected rats treated with vehicle or GH. Histograms showing mean \pm SEM of the fold-difference relative to the mean value of HSA + vehicle controls analyzed on the same blot. ${ }^{a} P<.05$ vs HSA controls. 
A

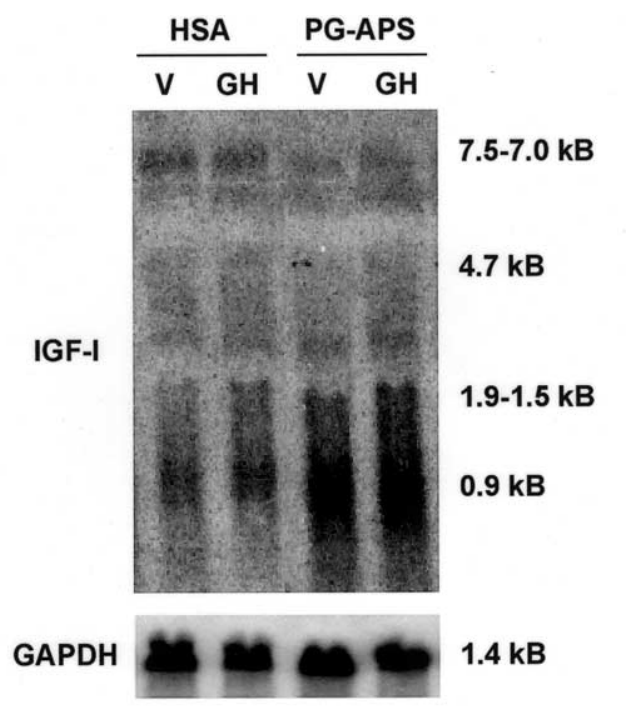

B

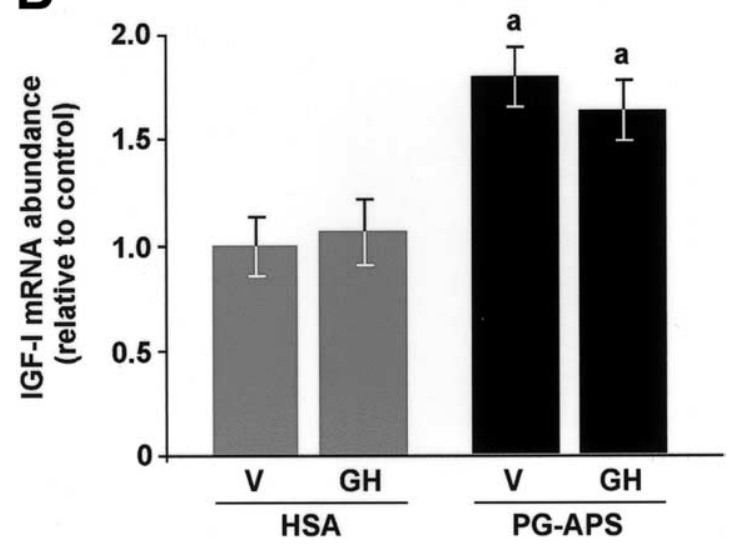

Figure 5. (A) Representative Northern blot showing IGF-I and control (GAPDH) mRNA expression in total RNA isolated from cecum. Treatments are indicated. $(B)$ Histograms showing mean \pm SEM of the fold-difference relative to the mean value of HSA + vehicle controls analyzed on the same blot. ${ }^{a} P<.05$ vs HSA controls.

levels in PG-APS-injected rats and did not significantly alter plasma IGF-I concentrations in HSA-injected rats. Abundance of cecal IGF-I mRNA was increased during PG-APS-induced colitis as shown previously in this animal model, ${ }^{29}$ but did not differ in $\mathrm{GH}$ vs vehicletreated rats (Figure 5).

\section{GH Increases SOCS-3 mRNA and Protein Abundance During PG-APS-Induced Colitis}

Expression of SOCS-3, which has been implicated as a negative regulator of intestinal inflammation, ${ }^{47}$ was assessed by Northern blot hybridization in total cecal RNA. SOCS-3 mRNA abundance was increased by 3-fold in PG-APS-injected rats that were administered GH $(P<.005)$ compared with PG-APS-injected rats given vehicle, but was not increased significantly in
GH-treated HSA-injected rats relative to vehicle control HSA rats (Figure $6 A$ ). SOCS-3 protein also was increased in GH-treated PG-APS-injected rats compared with vehicle-treated rats (Figure $6 B$ ). Linear regression analysis revealed that SOCS-3 mRNA abundance showed a significant inverse correlation with histologic fibrosis score $(r=-.74 ; P<.05)$ and cecal collagen mRNA abundance $(r=-.69 ; P<.05)$ in individual PG-APStreated rats, and SOCS-3 protein abundance showed a significant inverse correlation with cecal collagen protein $(r=-.62 ; P<.05)$, providing indirect evidence that increased SOCS-3 expression induced by GH during PG-APS-induced colitis could contribute to GH-dependent reduction in intestinal fibrosis. In HSA-injected control rats, there was no significant correlation between SOCS- 3 mRNA levels and cecal fibrosis score $(r=.02$; $P=.51)$ or collagen mRNA expression $(r=.04 ; P=$ .89), indicating that the inverse association between SOCS-3 and fibrosis occurs only during inflammation. Analyses of SOCS-1 and SOCS-2 mRNAs, other members of the family of suppressor of cytokine signaling known to be induced in intestine by GH in some settings, ${ }^{48}$ revealed very low constitutive expression and no induction by GH in HSA- or PG-APS-injected rats in total RNA isolated from cecum (data not shown).

\section{SOCS-3 mRNA Localizes to the Periphery of Granulomas}

In situ hybridization on cecal sections from PGAPS - and GH-treated rats localized SOCS- 3 mRNA to the periphery of serosal granulomas (Figure $7 E$ and $F$ ), correlating with sites of collagen accumulation visualized by Sirius red staining (compare Figure $7 C$ and $E$ ). In adjacent sections, SOCS- 3 sense control was negative, validating the specificity of hybridization signals obtained with the antisense probe. Cells at the periphery of granulomas in the PG-APS model were previously characterized as myofibroblasts $^{25}$ that deposit collagen protein, resulting in collagen surrounding the granuloma. SOCS-3 mRNA was barely detected in cecum of PG-APS given vehicle and HSA control animals, and expression could not be attributed conclusively to specific cell populations (data not shown).

GH in Combination With TNF $\alpha$, IL-6, IL-10, or PG-APS Rapidly Up-Regulates SOCS-3 mRNA Abundance in Cultured Intestinal Myofibroblasts

Cultured intestinal myofibroblasts were treated with GH, TNF $\alpha$, IL-6, IL-10, and PG-APS, alone or in combination with $\mathrm{GH}$, to determine which factors induce SOCS-3 expression in cultured intestinal myofibroblasts. No cytokine or PG-APS alone up-regulated 

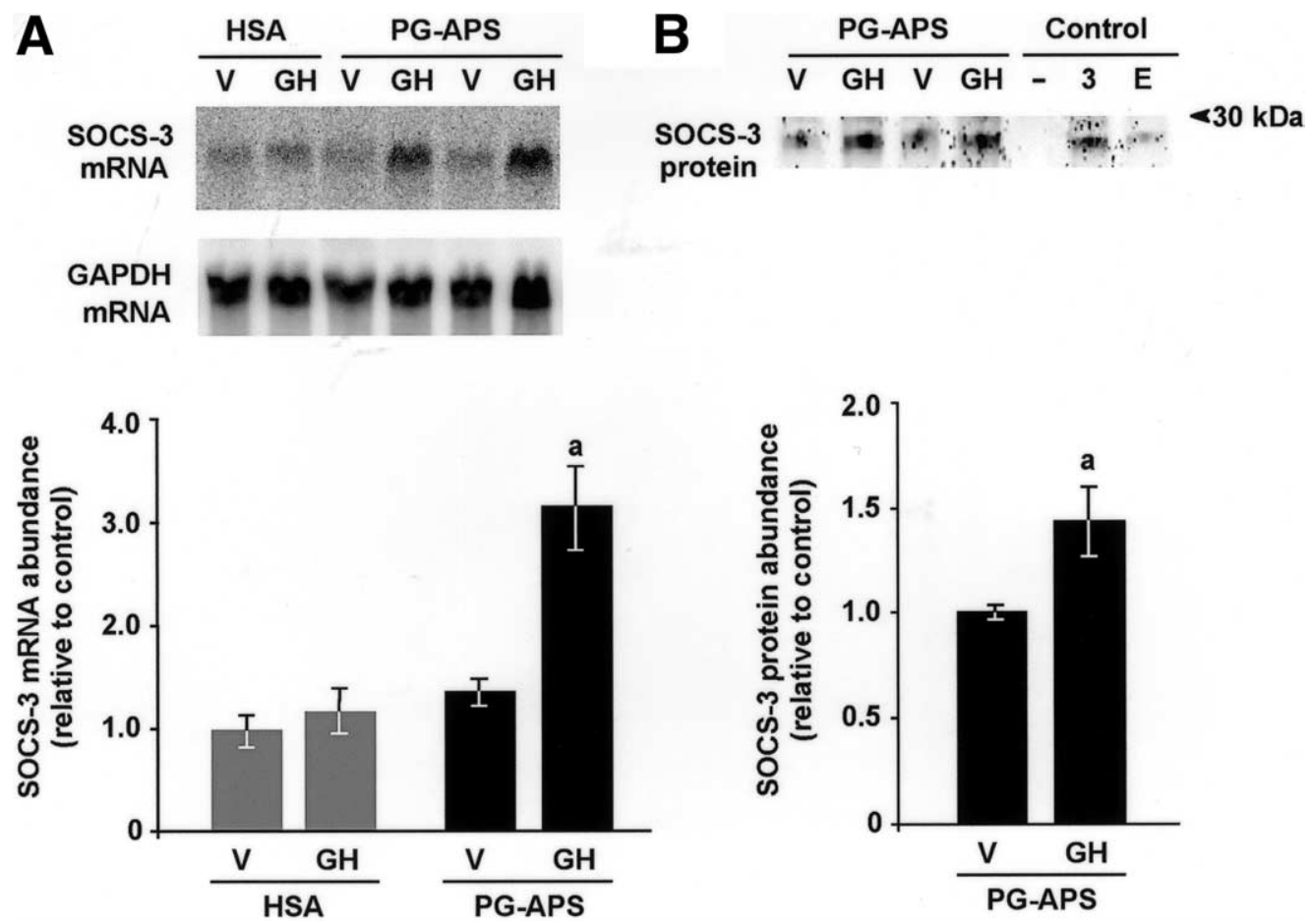

Figure 6. (A) Representative Northern blot showing SOCS-3 and control (GAPDH) mRNA expression in cecums of HSA- or PG-APS-injected rats treated with vehicle or GH. Values are mean \pm SEM of SOCS-3 mRNA abundance normalized to GAPDH expression relative to the mean value of HSA + vehicle controls analyzed on the same blot. ${ }^{a} P<.005$. (B) Representative Western immunoblot for SocS-3 protein from cecal protein extracts immunoprecipitated for SOCS-3. Omission of primary antibody during the immunoprecipitation was performed as a negative control ( - ). Protein isolated from Caco-2 cells transfected with a SOCS-3 expression vector was used as a positive control (3) compared with cells transfected with empty vector (E). Histograms showing mean \pm SEM of the fold-difference relative to the mean value of PG-APS + vehicle controls analyzed on the same blot. ${ }^{a} P<.05$ vs PG-APS + V.

SOCS-3 mRNA abundance, but TNF $\alpha$, IL-6, IL-10, and PG-APS, when given in combination with GH, all induced SOCS-3 expression (Figure 8).

\section{GH, IGF-I, and TNF $\alpha$ Induce Collagen Accumulation in Cultured Intestinal Myofibroblasts and SOCS-3 Inhibits This Effect}

To test whether SOCS-3 can modulate GH action on collagen accumulation, intestinal myofibroblasts stably transfected with a SOCS-3 expression vector or empty vector control were treated with GH. GH robustly stimulated collagen accumulation in empty vector-transfected cells and this effect was attenuated in SOCS-3-overexpressing cells (Figure 9). The effect of SOCS- 3 was not limited to GH because IGF-I and TNF $\alpha$ each induced collagen accumulation in empty vectortransfected cells, but SOCS-3 overexpression attenuated the effects of GH and IGF-I and eliminated the effects of $\mathrm{TNF} \alpha$ (Figure 9).

\section{Discussion}

Prior studies in animal models have indicated that GH promotes mucosal repair after chemically induced mucosal damage and acute intestinal inflammation..$^{21,23}$ Our study showed that GH does not exacerbate fibrosis associated with chronic PG-APS-induced transmural granulomatous enterocolitis. Rather, GH moderately reduced gross complications of inflammation associated with fibrosis such as adhesions and mesentery contractions and modestly reduced histologic and biochemical measures of fibrosis. These results of GH infusion in an animal model of chronic enterocolitis and fibrosis are reassuring with respect to potential complications of $\mathrm{GH}$ therapy in patients with IBD because they provide no evidence that $\mathrm{GH}$ worsens fibrosis, a serious complication that is common in patients with CD.

A second experiment in a small number of animals using an entirely different preparation of PG-APS revealed similar effects of $\mathrm{GH}$ to reduce gross gut scores for adhesions (vehicle, $3.5 \pm .5$; vs GH, $1.5 \pm .5$ ) and mesentery contractions (vehicle, $3.0 \pm .0$; vs GH, $1.5 \pm$ .5 ), as well as histologic fibrosis score (vehicle, $11.7 \pm .4$; vs $\mathrm{GH}, 8.9 \pm .5$ ), validating the reproducibility of the antifibrogenic effects of GH. The reduced fibrosis in $\mathrm{GH}$-treated rats could represent decreased synthesis and deposition of collagen, decreased myofibroblast proliferation, or a combination of both. The decrease in collagen 

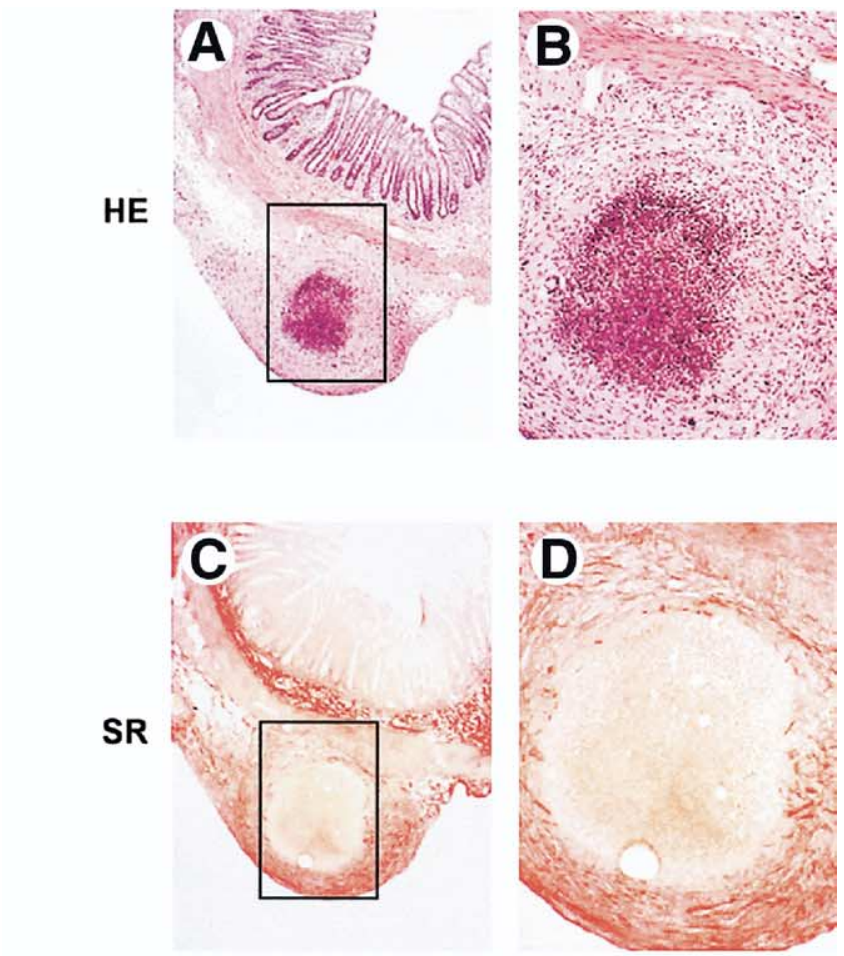

SOCS-3
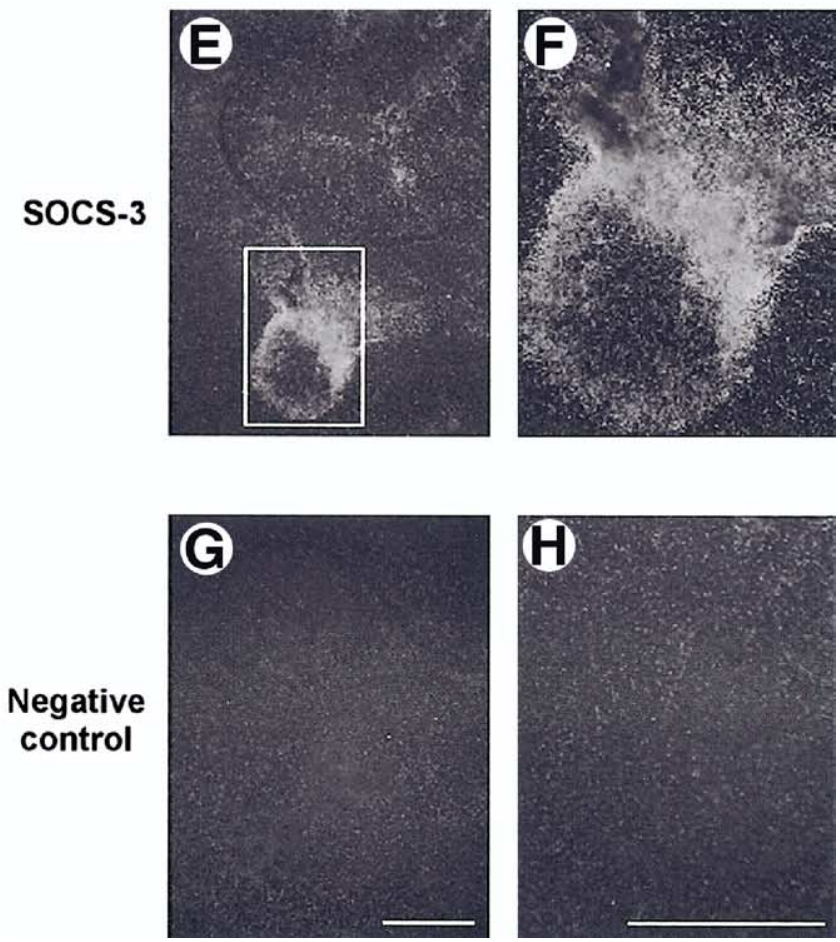

Figure 7. $(A-D)$ Bright-field and $(E, F)$ dark-field photomicrographs show in situ hybridization of SOCS-3 mRNA $(E, F)$ at the periphery of a granuloma (inside box) in the serosa of a PG-APS + GH rat. $(C, D)$ SOCS-3 mRNA localizes to sites of collagen deposition as revealed in adjacent sections by Sirius red staining. $(G, H)$ A SOCS-3 sense RNA probe was used as a negative control and gave a negative signal. HE, H\&E-stained adjacent section to show histology. SR, Sirius redstained adjacent section to indicate localization of collagen protein (red stain). Box indicates area shown in higher magnification in the adjacent column. $(G, H)$ Bar $=500 \mu \mathrm{m}$.
mRNA, protein, and histologic fibrosis scores in $\mathrm{GH}-$ treated rats supports an effect on collagen synthesis and accumulation. We did not evaluate directly the effects of GH on proliferation of mesenchymal cells at sites of collagen deposition. Attempts to identify proliferating mesenchymal cells by bromodeoxyuridine incorporation or immunostaining have proved problematic (Lund, unpublished data, November 2000). This is because it is difficult to distinguish mesenchymal cells from numerous immune cells labeled with bromodeoxyuridine. Thus, we cannot formally exclude an effect of $\mathrm{GH}$ on mesenchymal cell proliferation, although it should be noted that in cultured myofibroblasts GH has little or no effect on proliferation. ${ }^{49}$ Although the reduction in fibrosis by GH was modest, it was verified by 4 different measures that include gross gut disease scores for adhesions and mesentery contractions, histologic fibrosis

A

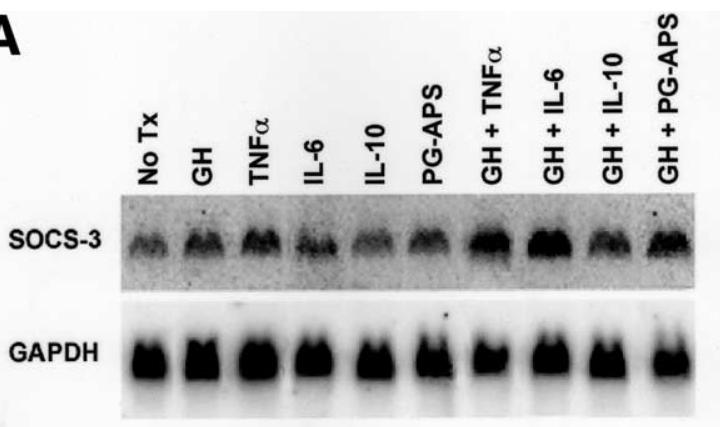

B

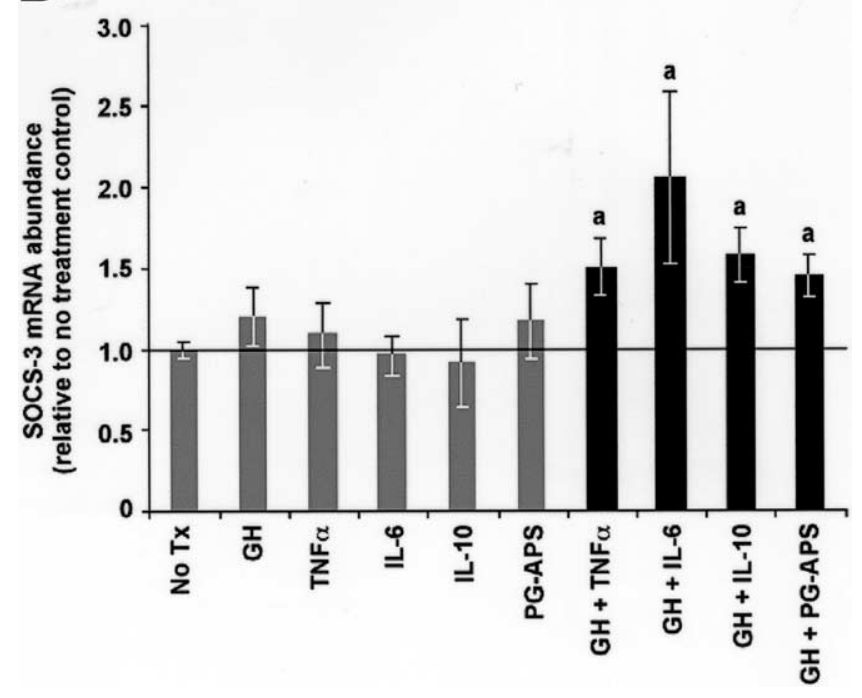

Figure 8. Representative Northern blot showing SOCS-3 and control (GAPDH) mRNA expression in cultured intestinal myofibroblasts treated with GH alone or in combination with various cytokines or PG-APS. Values are mean \pm SEM of SOCS-3 mRNA abundance normalized to GAPDH expression relative to the mean value of no treatment (No Tx) controls analyzed on the same blot. ${ }^{a} P<.05$ vs no treatment; $n \geq 3$ per treatment. 


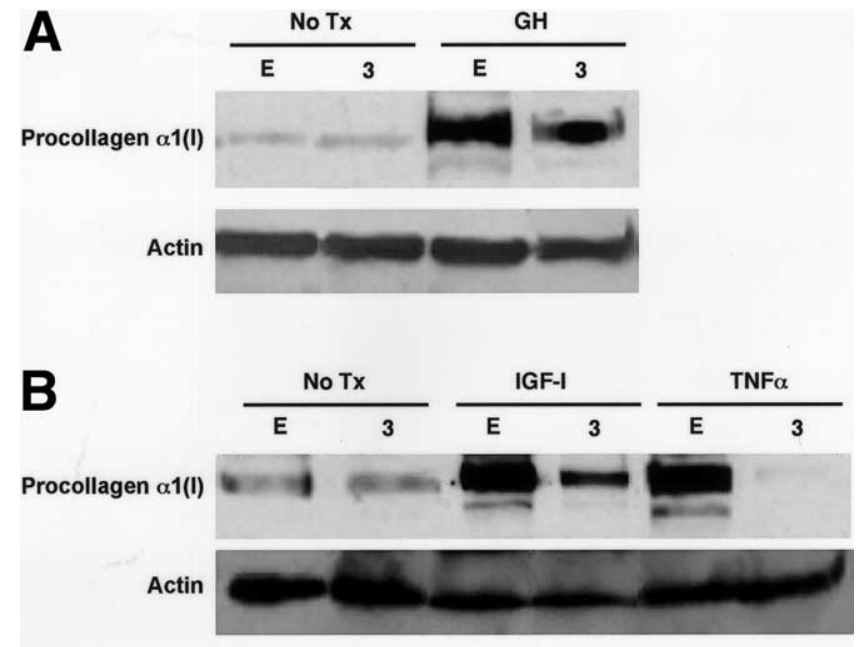

C

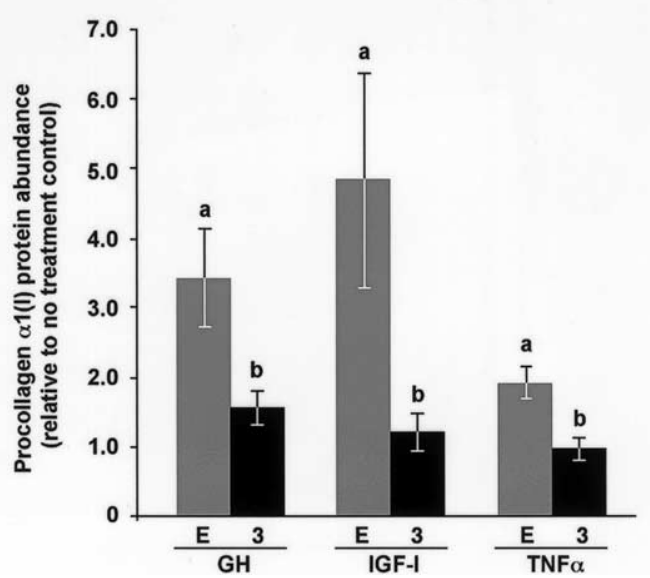

Figure 9. $(A)$ Western blots of procollagen $\alpha 1(I)$ protein accumulation and actin (control) in intestinal myofibroblasts transfected with SOCS-3 (3) or empty vector (E) expression constructs and treated with $\mathrm{GH}$. (B) Western blots showing procollagen $\alpha 1(\mathrm{I})$ and control protein abundance in intestinal myofibroblasts transfected with SOCS-3 or empty vector expression constructs and treated with IGF-I or TNF $\alpha$. (C) Procollagen $\alpha 1(I)$ protein abundance normalized to control protein abundance, relative to no treatment control value (set at 1 ) analyzed on the same blot. $\mathrm{n} \geq 5$ per treatment group. a $P<.05$ vs no treatment control, ${ }^{b} P<.05$ vs empty vector-transfected cells of the same treatment.

score, and type I collagen mRNA and protein abundance. Importantly, these results provide no evidence that $\mathrm{GH}$ will exacerbate fibrosis in patients with IBD. It is important to emphasize that GH was given therapeutically in a situation of ongoing chronic inflammation. Given that few, if any, current treatments are known to reduce complications of fibrosis, this effect in an experimental model indicates that evaluation of $\mathrm{GH}$ action on fibrosis in humans with SBS or IBD is warranted.

Despite modest beneficial effects of $\mathrm{GH}$ on fibrosis, therapeutic GH had no effect on intestinal inflammation assessed by histologic scoring of acute and chronic colitis, grossly evident cecal wall thickening and granulomas, or the level of expression of IL-1 $\beta$ and TNF $\alpha$. The lack of effect of $\mathrm{GH}$ on inflammation is consistent with our prior findings in GH-transgenic mice in which GH overexpression did not alter the severity of inflammation or mucosal damage induced by dextran sodium sulfate administration, although GH-transgenic mice did show more rapid epithelial repair and crypt regeneration after dextran sodium sulfate treatment. ${ }^{23}$ We did not examine effects of GH on epithelial responses to PG-APS-induced colitis in the present study, largely because the PG-APS model is one of progressive worsening of chronic submucosal-predominant inflammation that does not lend itself readily to studies of epithelial repair. However, the lack of effect of GH on inflammation indicates that even if $\mathrm{GH}$ did affect the epithelium in this model, this does not improve the course of chronic inflammation. Prior studies reporting anti-inflammatory actions of $\mathrm{GH}^{22}$ or effects of $\mathrm{GH}$ on mucosal repair ${ }^{50}$ involved $\mathrm{GH}$ administration before and during the induction of mucosal damage and inflammation. We deliberately administered GH therapeutically after the onset of chronic inflammation to best mimic the clinical actions of GH treatment during active, chronic IBD. The absence of an anti-inflammatory effect of $\mathrm{GH}$ on the intestine when given during active, chronic disease in the PG-APS model, but anti-inflammatory actions when given before disease onset, indicates that timing of $\mathrm{GH}$ therapy relative to time of disease onset or remission may be critical to maximizing the benefits of $\mathrm{GH}$ therapy in CD patients.

In the PG-APS model, GH treatment did result in moderate but significant reductions in the severity of joint inflammation, indicated by the smaller increase in joint diameter in GH-treated rats. Thus, GH did improve one of the extraintestinal inflammatory complications secondary to PG-APS-induced colitis. We did not perform joint histology or biochemical analysis of joint inflammation in this study, but the induction of SOCS-3 in intestine by $\mathrm{GH}$ is intriguing given findings that adenovirus therapy with SOCS-3 expression constructs improved arthritis in mouse models of antigen-induced and collagen-induced arthritis. ${ }^{51}$ Therefore, GH may improve joint inflammation by inducing SOCS-3 and the study of the effects of GH on SOCS-3 or of other mechanisms of action in joint inflammation in animal models of IBD or in patients with IBD is warranted in the future.

Because many actions of $\mathrm{GH}$ are mediated through IGF-I, and IGF-I is implicated as a mediator of fibrosis in $\mathrm{CD},{ }^{1}$ we had anticipated that $\mathrm{GH}$ may increase plasma or local levels of IGF-I and thus indirectly increase collagen synthesis or fibrosis during PG-APS-induced colitis. PGAPS inflammation increased plasma IGF-I concentrations 
compared with control rats, but GH treatment showed no effect compared with vehicle infusion. This lack of response could be caused by the relatively low dose of GH used during the infusion, which was chosen to more closely replicate dosing in humans. In addition, it is well established that inflammation leads to a situation of $\mathrm{GH}$ resistance in the liver such that GH is unable to induce IGF-I synthesis. ${ }^{52}$ Thus, the absence of an effect of GH to increase plasma IGF-I or body weight gain likely reflects this phenomenon. Cecal expression of IGF-I was increased during PG-APS inflammation, as shown previously, ${ }^{29}$ but did not change with GH treatment. This indicates that systemic administration of low doses of GH does not increase local IGF-I expression further in the intestine above the already increased levels associated with chronic intestinal inflammation. This finding is especially important because considerable evidence suggests locally expressed, mesenchymal cell-derived IGF-I, acting in a paracrine and/or autocrine manner, may be a mediator of inflammation-induced intestinal fibrosis. ${ }^{1}$

In the liver, SOCS proteins have been shown to be induced by $\mathrm{GH}$, and in settings of hepatic or systemic inflammation to prevent GH induction of IGF-I. ${ }^{52} \mathrm{Re}-$ cent findings in a rat model of total parenteral nutrition indicate that GH induces SOCS-2 in the small intestine and colon and that SOCS-2 can limit the proliferative actions of GH and IGF-I on the intestinal epithelium. ${ }^{48}$ We therefore analyzed SOCS expression in cecum of HSA- or PG-APS-injected rats given vehicle or GH with the rationale that $\mathrm{GH}$ induction of SOCS could limit the fibrogenic actions of $\mathrm{GH}$ or endogenously up-regulated IGF-I that appears to mediate or contribute to fibrosis during intestinal inflammation. In contrast to the total parenteral nutrition model, GH administered to HSA control rats induced neither SOCS-2 nor SOCS-3 mRNA. At present, we have no experimental evidence to establish why cecal levels of SOCS-2 were not up-regulated in HSA rats by GH treatment as observed in total parenteral nutrition controls, except that the dose of $\mathrm{GH}$ was lower and the duration of treatment was longer. In addition, oral feeding in the current study vs total parenteral nutrition feeding, when $\mathrm{GH}$ was found to induce SOCS-2, could impact on GH induction of SOCS.

However, in PG-APS-injected rats, GH robustly induced SOCS-3 mRNA and protein relative to vehicleinjected controls. This is intriguing because SOCS- 3 is implicated increasingly as a negative modulator of the actions of proinflammatory cytokines on macrophages and $\mathrm{T}$ cells. ${ }^{32,33}$ However, in the PG-APS model, GH induction of SOCS-3 was not associated with reduced inflammation, nor did SOCS-3 levels show a significant negative correlation with measures of inflammation, as might be anticipated if, in this setting, SOCS-3 had anti-inflammatory actions. Instead, regression analysis revealed SOCS-3 mRNA abundance showed a significant inverse correlation with cecum fibrosis score and collagen mRNA abundance in individual PG-APS-treated rats and SOCS-3 protein abundance showed a significant inverse correlation with collagen protein abundance. However, HSA control rats showed no correlation between SOCS-3 mRNA expression and cecum fibrosis score or collagen mRNA expression. Furthermore, in situ hybridization revealed SOCS-3 mRNA localized to the periphery of granulomas in PG-APS-injected rats treated with $\mathrm{GH}$, indicating SOCS-3 is induced in a relevant cell population. Previous studies have localized GH receptor expression in the intestinal mucosa layer and to mesenchymal cells in submucosa, muscularis, and serosa layers, ${ }^{53}$ consistent with responsiveness of these cells to $\mathrm{GH}$ in vivo. Because it is difficult in in vivo studies to show directly that $\mathrm{GH}$ induction of SOCS-3 mediates the reduction in fibrosis, we used simple cell culture models to test this possibility.

Treatment of intestinal myofibroblasts with $\mathrm{GH}$, TNF $\alpha$, IL-6, IL-10, or PG-APS alone failed to induce SOCS-3 expression. However, GH in combination with these factors rapidly induced SOCS-3. These results indicate $\mathrm{GH}$, in combination with other cytokines expressed during inflammation, can up-regulate SOCS-3 expression in intestinal myofibroblasts, but SOCS-3 is not up-regulated when $\mathrm{GH}$ is administered alone. This is important mechanistically given our in vivo evidence that SOCS-3 induction correlated with reduced fibrosis and more direct evidence in cultured myofibroblasts that SOCS-3 overexpression directly inhibited GH-, IGF-Ior TNF $\alpha$-induced collagen accumulation. These results support a model (Figure 10) that induction of SOCS-3 expression in the inflamed intestine by $\mathrm{GH}$, in combination with other cytokines, decreases the fibrogenic actions of IGF-I and TNF $\alpha$, which are favored as mediators of fibrosis, and therefore SOCS-3 mediates antifibrogenic rather than profibrogenic actions of $\mathrm{GH}$. One surprising finding in the present study was that SOCS-3 mRNA expression was not up-regulated in the cecum of rats with chronic PG-APS-induced enterocolitis vs HSA controls in the absence of GH therapy. This contrasts with increases in SOCS-3 expression reported in a number of IBD models, including the dextran sodium sulfate model and the IL-10 knockout mouse. ${ }^{47}$ It seems likely that the difference in up-regulation of endogenous SOCS-3 across IBD models reflects variations in chronicity of inflammation and the particular cytokine milieu because it is known that SOCS-3 mRNA is induced cyclically, has a short half-life, and has been linked most 


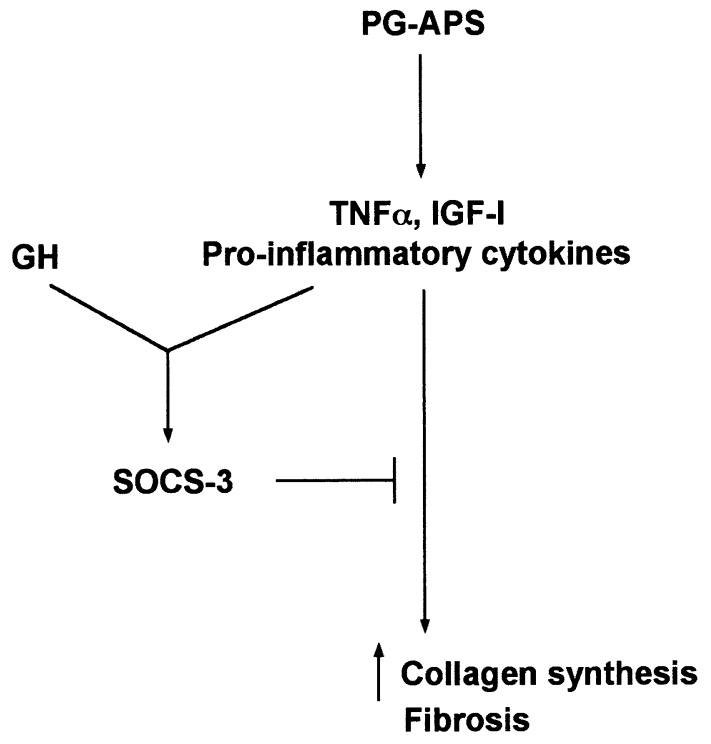

Figure 10. Hypothetical model showing PG-APS induction of proinflammatory cytokines that, together with therapeutic $\mathrm{GH}$, induce SOCS-3. SOCS-3 decreases the fibrogenic actions of proinflammatory cytokines including TNF $\alpha$, IGF-I, and GH itself, resulting in decreased intestinal fibrosis.

closely to IL-6 up-regulation in other models. ${ }^{54}$ Nonetheless, our findings that GH induces SOCS- 3 in a chronic granulomatous enterocolitis model that shares features with $\mathrm{CD}$ and the new evidence that this induction inversely correlates with severity of fibrosis, rather than inflammation, suggest a role of SOCS- 3 as an antifibrogenic signaling intermediate in mesenchymal cells that warrants further investigation.

In conclusion, our findings in the PG-APS rat model of chronic intestinal inflammation and fibrosis indicate that GH treatment does not exacerbate intestinal fibrosis and has a modest therapeutic benefit to decrease intestinal fibrosis during chronic disease. These data extend previous findings suggesting beneficial effects of rhGH used as therapy in patients with CD and SBS. ${ }^{10-13,16,18-20}$ Our study of therapeutic GH in an animal model of chronic intestinal inflammation and fibrosis provides no evidence that $\mathrm{GH}$ will exacerbate fibrosis in IBD, but instead provides new evidence that GH may have antifibrogenic actions mediated by the induction of SOCS-3 expression.

\section{References}

1. Zimmermann E, Lund PK. Fibrogenesis. In: Sartor RB, Sandborn WJ, eds. Kirsner's inflammatory bowel diseases. 6th ed. Philadelphia: Elsevier, 2004:219-229.

2. Graham MF, Diegelmann RF, Elson CO, Lindblad WJ, Gotschalk N, Gay S, Gay R. Collagen content and types in the intestinal strictures of Crohn's disease. Gastroenterology 1988;94:257-265.

3. Matthes $\mathrm{H}$, Herbst $\mathrm{H}$, Schuppan D, Stallmach A, Milani S, Stein H, Riecken EO. Cellular localization of procollagen gene transcripts in inflammatory bowel diseases. Gastroenterology 1992;102: 431-442.
4. Powell DW, Mifflin RC, Valentich JD, Crowe SE, Saada JI, West AB. Myofibroblasts. II. Intestinal subepithelial myofibroblasts. Am J Physiol 1999;277:C183-C201.

5. Powell DW, Mifflin RC, Valentich JD, Crowe SE, Saada JI, West AB. Myofibroblasts. I. Paracrine cells important in health and disease. Am J Physiol 1999;277:C1-C9.

6. Pucilowska JB, McNaughton KK, Mohapatra NK, Hoyt EC, Zimmermann EM, Sartor RB, Lund PK. IGF-I and procollagen alpha1(I) are coexpressed in a subset of mesenchymal cells in active Crohn's disease. Am J Physiol 2000;279:G1307-G1322.

7. Van Assche G, Geboes K, Rutgeerts P. Medical therapy for Crohn's disease strictures. Inflamm Bowel Dis 2004;10:55-60.

8. Becker JM. Surgical therapy for ulcerative colitis and Crohn's disease. Gastroenterol Clin North Am 1999;28:371-390, viii-ix.

9. Scolapio JS, Camilleri M, Fleming CR, Oenning LV, Burton DD, Sebo TJ, Batts KP, Kelly DG. Effect of growth hormone, glutamine, and diet on adaptation in short-bowel syndrome: a randomized, controlled study. Gastroenterology 1997;113:1074-1081.

10. Ellegard L, Bosaeus I, Nordgren S, Bengtsson BA. Low-dose recombinant human growth hormone increases body weight and lean body mass in patients with short bowel syndrome. Ann Surg 1997;225:88-96.

11. Byrne TA, Persinger RL, Young LS, Ziegler TR, Wilmore DW. A new treatment for patients with short-bowel syndrome. Growth hormone, glutamine, and a modified diet. Ann Surg 1995;222:243-254.

12. Cukier C, Waitzberg DL, Borges VC, Silva Mde L, Gama-Rodrigues J, Pinotti HW. Clinical use of growth hormone and glutamine in short bowel syndrome. Rev Hosp Clin Fac Med Sao Paulo 1999; 54:29-34.

13. Seguy D, Vahedi K, Kapel N, Souberbielle JC, Messing B. Lowdose growth hormone in adult home parenteral nutrition-dependent short bowel syndrome patients: a positive study. Gastroenterology 2003;124:293-302.

14. Szkudlarek J, Jeppesen PB, Mortensen PB. Effect of high dose growth hormone with glutamine and no change in diet on intestinal absorption in short bowel patients: a randomised, double blind, crossover, placebo controlled study. Gut 2000;47:199-205.

15. Scolapio JS. Effect of growth hormone, glutamine, and diet on body composition in short bowel syndrome: a randomized, controlled study. JPEN J Parenter Enteral Nutr 1999;23:309-313.

16. Byrne TA, Morrissey TB, Nattakom TV, Ziegler TR, Wilmore DW. Growth hormone, glutamine, and a modified diet enhance nutrient absorption in patients with severe short bowel syndrome. JPEN J Parenter Enteral Nutr 1995;19:296-302.

17. Scolapio JS. Tales from the crypt. Gastroenterology $2003 ; 124$ 561-564.

18. Mauras N, George D, Evans J, Milov D, Abrams S, Rini A, Welch S, Haymond MW. Growth hormone has anabolic effects in glucocorticosteroid-dependent children with inflammatory bowel disease: a pilot study. Metabolism 2002;51:127-135.

19. Henker J. Therapy with recombinant growth hormone in children with Crohn's disease and growth failure. Eur J Pediatr 1996;155: 1066-1067.

20. Slonim AE, Bulone L, Damore MB, Goldberg T, Wingertzahn MA, McKinley MJ. A preliminary study of growth hormone therapy for Crohn's disease. N Engl J Med 2000;342:1633-1637.

21. Christensen $\mathrm{H}$, Flyvbjerg $\mathrm{A}$, Orskov $\mathrm{H}$, Laurberg $\mathrm{S}$. Effect of growth hormone on the inflammatory activity of experimental colitis in rats. Scand J Gastroenterol 1993;28:503-511.

22. Kara $E$, Sungurtekin $H$, Sungurtekin $U$, Alkanat $M$, Ilkgul $O$. The effect of recombinant human growth hormone (rhGH) on trinitrobenzene sulfonic acid-induced colitis in rats: an experimental study. Inflamm Bowel Dis 2004;10:112-115.

23. Williams KL, Fuller CR, Dieleman LA, DaCosta CM, Haldeman KM, Sartor RB, Lund PK. Enhanced survival and mucosal repair after dextran sodium sulfate-induced colitis in transgenic mice that overexpress growth hormone. Gastroenterology 2001;120:925-937. 
24. Fruchtman S, Simmons JG, Fuller CR, Greenhalgh CJ, Lund PK. Suppressors of cytokine signaling (SOCS) limit fibrogenic actions of growth hormone and insulin-like growth factor-I in intestinal myofibroblasts. Gastroenterology 2004;126:A-138.

25. van Tol EA, Holt L, Li FL, Kong FM, Rippe R, Yamauchi M, Pucilowska J, Lund PK, Sartor RB. Bacterial cell wall polymers promote intestinal fibrosis by direct stimulation of myofibroblasts. Am J Physiol 1999;277:G245-G255.

26. Sartor RB, Herfarth $\mathrm{H}$, Van Tol EAF. Bacterial cell wall polymerinduced granulomatous inflammation. Methods 1996;9:233-247.

27. Sartor RB, Cromartie WJ, Powell DW, Schwab JH. Granulomatous enterocolitis induced in rats by purified bacterial cell wall fragments. Gastroenterology 1985;89:587-595.

28. Greig ER, Rampton DS. Management of Crohn's Disease. New York: Martin Dunitz, 2003.

29. Zimmermann EM, Sartor RB, McCall RD, Pardo M, Bender D, Lund PK. Insulinlike growth factor I and interleukin 1 beta messenger RNA in a rat model of granulomatous enterocolitis and hepatitis. Gastroenterology 1993;105:399-409.

30. Lawrance IC, Fiocchi C, Chakravarti S. Ulcerative colitis and Crohn's disease: distinctive gene expression profiles and novel susceptibility candidate genes. Hum Mol Genet 2001;10:445-456.

31. Lawrance IC, Maxwell L, Doe W. Inflammation location, but not type, determines the increase in TGF-beta1 and IGF-1 expression and collagen deposition in IBD intestine. Inflamm Bowel Dis 2001;7:16-26.

32. Croker BA, Krebs DL, Zhang JG, Wormald S, Willson TA, Stanley EG, Robb L, Greenhalgh CJ, Forster I, Clausen BE, Nicola NA, Metcalf D, Hilton DJ, Roberts AW, Alexander WS. SOCS3 negatively regulates IL-6 signaling in vivo. Nat Immunol 2003;4:540-545.

33. Lovato P, Brender C, Agnholt J, Kelsen J, Kaltoft K, Svejgaard A, Eriksen KW, Woetmann A, Odum N. Constitutive STAT3 activation in intestinal T cells from patients with Crohn's disease. J Biol Chem 2003;278:16777-16781.

34. Ortiz LA, Lasky J, Gozal E, Ruiz V, Lungarella G, Cavarra E, Brody AR, Friedman M, Pardo A, Selman M. Tumor necrosis factor receptor deficiency alters matrix metalloproteinase 13/tissue inhibitor of metalloproteinase 1 expression in murine silicosis. Am J Respir Crit Care Med 2001;163:244-252.

35. Guo G, Morrissey J, McCracken R, Tolley T, Liapis H, Klahr S. Contributions of angiotensin II and tumor necrosis factor-alpha to the development of renal fibrosis. Am J Physiol 2001;280:F777F785.

36. Fox A, Brown RR, Anderle SK, Chetty C, Cromartie WJ, Gooder H, Schwab JH. Arthropathic properties related to the molecular weight of peptidoglycan-polysaccharide polymers of streptococcal cell walls. Infect Immun 1982;35:1003-1010.

37. Dahly EM, Miller ME, Lund PK, Ney DM. Postreceptor resistance to exogenous growth hormone exists in the jejunal mucosa of parenterally fed rats. J Nutr 2004;134:530-537.

38. Park JH, Vanderhoof JA. Growth hormone did not enhance mucosal hyperplasia after small-bowel resection. Scand J Gastroenterol 1996;31:349-354.

39. McCall RD, Haskill S, Zimmermann EM, Lund PK, Thompson RC, Sartor RB. Tissue interleukin 1 and interleukin-1 receptor antagonist expression in enterocolitis in resistant and susceptible rats. Gastroenterology 1994;106:960-972.

40. Ohneda K, Ulshen MH, Fuller CR, D'Ercole AJ, Lund PK. Enhanced growth of small bowel in transgenic mice expressing human insulin-like growth factor I. Gastroenterology 1997; 112:444-454.

41. Savendahl L, Underwood LE, Haldeman KM, Ulshen MH, Lund PK. Fasting prevents experimental murine colitis produced by dextran sulfate sodium and decreases interleukin-1 beta and insulin-like growth factor I messenger ribonucleic acid. Endocrinology 1997;138:734-740.
42. Rosell DR, Akama KT, Nacher J, McEwen BS. Differential expression of suppressors of cytokine signaling-1, -2 , and -3 in the rat hippocampus after seizure: implications for neuromodulation by gp130 cytokines. Neuroscience 2003;122:349-358.

43. Simmons JG, Pucilowska JB, Keku TO, Lund PK. IGF-I and TGFbeta1 have distinct effects on phenotype and proliferation of intestinal fibroblasts. Am J Physiol 2002;283:G809-G818.

44. Kaiser GC, Polk DB. Tumor necrosis factor alpha regulates proliferation in a mouse intestinal cell line. Gastroenterology 1997; 112:1231-1240.

45. Adams TE, Hansen JA, Starr R, Nicola NA, Hilton DJ, Billestrup N. Growth hormone preferentially induces the rapid, transient expression of SOCS-3, a novel inhibitor of cytokine receptor signaling. J Biol Chem 1998;273:1285-1287.

46. Starr R, Willson TA, Viney EM, Murray LJ, Rayner JR, Jenkins BJ, Gonda TJ, Alexander WS, Metcalf D, Nicola NA, Hilton DJ. A family of cytokine-inducible inhibitors of signalling. Nature 1997;387: 917-921.

47. Suzuki A, Hanada T, Mitsuyama K, Yoshida T, Kamizono S, Hoshino T, Kubo M, Yamashita A, Okabe M, Takeda K, Akira S, Matsumoto S, Toyonaga A, Sata M, Yoshimura A. CIS3/SOCS3/ SSI3 plays a negative regulatory role in STAT3 activation and intestinal inflammation. J Exp Med 2001;193:471-481.

48. Miller ME, Michaylira CZ, Simmons JG, Ney DM, Dahly EM, Heath JK, Lund PK. Suppressor of cytokine signaling-2: a growth hormone-inducible inhibitor of intestinal epithelial cell proliferation. Gastroenterology 2004;127:570-581.

49. Fruchtman S, Simmons JG, Michaylira CZ, Miller ME, Greenhalgh CJ, Ney DM, Lund PK. Suppressor of cytokine signaling-2 (SOCS-2) modulates the fibrogenic actions of GH and IGF-I in intestinal mesenchymal cells. Am J Physiol 2005 (in press).

50. Fukushima R, Saito H, Inoue T, Fukatsu K, Inaba T, Han I, Furukawa S, Lin MT, Muto T. Prophylactic treatment with growth hormone and insulin-like growth factor I improve systemic bacterial clearance and survival in a murine model of burn-induced gut-derived sepsis. Burns 1999;25:425-430.

51. Shouda T, Yoshida T, Hanada T, Wakioka T, Oishi M, Miyoshi K, Komiya S, Kosai K, Hanakawa Y, Hashimoto K, Nagata K, Yoshimura A. Induction of the cytokine signal regulator SOCS3/ CIS3 as a therapeutic strategy for treating inflammatory arthritis. J Clin Invest 2001;108:1781-1788.

52. Hong-Brown LQ, Brown CR, Cooney RN, Frost RA, Lang $\mathrm{CH}$. Sepsis-induced muscle growth hormone resistance occurs independently of STAT5 phosphorylation. Am J Physiol 2003;285: E63-E72.

53. Lobie PE, Breipohl W, Waters MJ. Growth hormone receptor expression in the rat gastrointestinal tract. Endocrinology 1990; 126:299-306.

54. Greenhalgh CJ, Miller ME, Hilton DJ, Lund PK. Suppressors of cytokine signaling: relevance to gastrointestinal function and disease. Gastroenterology 2002;123:2064-2081.

Received October 16, 2004. Accepted March 30, 2005.

Address requests for reprints to: $P$. Kay Lund/Arianne Theiss, CB\#7545, Department of Cell and Molecular Physiology, University of North Carolina at Chapel Hill, Chapel Hill, North Carolina 27599-7545. e-mail: empk@med.unc.edu; fax: (919) 966-6927.

Supported by National Institute of Diabetes and Digestive and Kidney Diseases grant R01 DK-47769 (to P.K.L., R.B.S.). This study was facilitated by the Molecular Histopathology Core of the Center for Gastrointestinal Biology and Disease (National Institutes of Health P30-DK-34987).

The authors thank Kirk McNaughton for his expert assistance with histology, which was instrumental for both fibrosis and inflammation scoring. 